NBER WORKING PAPER SERIES

\title{
WORKING THROUGH THE DISTRIBUTION: MONEY IN THE SHORT AND LONG RUN
}

\author{
Guillaume Rocheteau \\ Pierre-Olivier Weill \\ Tsz-Nga Wong
}

Working Paper 21779

http://www.nber.org/papers/w21779

\author{
NATIONAL BUREAU OF ECONOMIC RESEARCH \\ 1050 Massachusetts Avenue \\ Cambridge, MA 02138 \\ December 2015
}

We thank for their comments participants at the 2015 West Coast Search-and-Matching Workshop at the Federal Reserve Bank of San Francisco, 2015 annual meeting of the Society of Economic Dynamics, 2015 Summer Workshop on Money, Banking, Payments and Finance at the Federal Reserve Bank of St Louis, and seminar participants at Simon Fraser University, University of Paris 2, and Banque de France. The views expressed herein are those of the authors and do not necessarily reflect the views of the National Bureau of Economic Research.

NBER working papers are circulated for discussion and comment purposes. They have not been peerreviewed or been subject to the review by the NBER Board of Directors that accompanies official NBER publications.

(C) 2015 by Guillaume Rocheteau, Pierre-Olivier Weill, and Tsz-Nga Wong. All rights reserved. Short sections of text, not to exceed two paragraphs, may be quoted without explicit permission provided that full credit, including (C) notice, is given to the source. 
Working through the Distribution: Money in the Short and Long Run

Guillaume Rocheteau, Pierre-Olivier Weill, and Tsz-Nga Wong

NBER Working Paper No. 21779

December 2015

JEL No. E0,E4,E52

\begin{abstract}
$\underline{\text { ABSTRACT }}$
We construct a tractable model of monetary exchange with search and bargaining that features a nondegenerate distribution of money holdings in which one can study the short-run and long-run effects of changes in the money supply. While money is neutral in the long run, a one-time money injection in a centralized market with flexible prices generates an increase in aggregate real balances in the short run, a decrease in the rate of return of money, and a redistribution of consumption levels across agents. The price level in the short run varies in a non-monotonic fashion with the size of the money injection, e.g., small injections can lead to short-run deflation while large injections generate inflation. We extend our model to include employment risk and show that repeated money injections can raise output and welfare when unemployment is high.
\end{abstract}

Guillaume Rocheteau

Department of Economics

University of California at Irvine

3151 Social Science Plaza

Irvine, California 9269

grochete@uci.edu

Pierre-Olivier Weill

Department of Economics

University of California, Los Angeles

Bunche Hall 8283

Los Angeles, CA 90095

and NBER

poweill@econ.ucla.edu

\author{
Tsz-Nga Wong \\ Research Department \\ Bank of Canada \\ 234 Laurier Avenue West \\ Ottawa, Ontario, Canada \\ K1A 0G9 \\ purpleteeth@gmail.com
}




\section{Introduction}

We develop a tractable model of monetary exchange with random matching and bargaining that features non-degenerate distributions of money holdings and prices. We build on the workhorse of modern monetary theory, the model of Lagos and Wright (2005), in which agents trade alternatively in decentralized markets, with random search and bargaining, and in centralized markets with competitive pricing. Despite the presence of idiosyncratic risk, the Lagos-Wright model is analytically tractable due to preferences that eliminate wealth effects in order to keep the distribution of money holdings degenerate. ${ }^{1}$ Our model provides a simple and natural departure from the Lagos-Wright environment leading to ex-post heterogeneity in money holdings while preserving tractability. By bringing the interplay between risk sharing and self-insurance to the center stage of the analysis, our model generates new insights for classical, yet topical, questions pertaining to the short-run and long-run effects of changes in the money supply. Examples of questions our model can address include: Does a one-time increase in the money supply affect aggregate real balances in the short run, thereby creating non-neutralities? Can a contractionary shock to monetary policy generate short-run inflation? Are the effects of an increase in the money supply monotone with the size of the money injection? Are they long lasting? Can anticipated inflation raise output and welfare?

In order to answer these questions we adopt a version of the Lagos-Wright model with a single change: we impose a finite (possibly stochastic) bound, $\bar{h}$, on agents' endowment of labor. ${ }^{2}$ Whenever the feasibility constraint on agents' labor supply, $h \leq \bar{h}$, binds, wealth effects become operational: individual real balances depend on past trading histories, value functions are strictly concave in money holdings, and the distribution of money holdings is non-degenerate. Yet, the model remains tractable and can be solved in closed formincluding distributions and value functions - for a large class of equilibria. When it cannot be solved in closed form, the equilibrium has a simple recursive structure allowing it to be easily computed.

The key ingredients for the tractability of the model are as follows. First, following Rocheteau and Wright (2005) and Lagos and Rocheteau (2005), LRW hereafter, there is heterogeneity in terms of agents' role in pairwise meetings: some agents are always buyers in bilateral matches in the decentralized goods market (think of households) while other agents are always sellers (think of retailers). Sellers, who are riskneutral in terms of their centralized-market consumption, do not hold any real balances. As a result, buyers effectively trade with a representative seller. Second, the terms of trade in pairwise meetings are set by buyers, allowing us to analyze savings and pricing decisions through a single dynamic programing problem.

\footnotetext{
${ }^{1}$ The Lagos-Wright model discards distributional effects not because they are thought to be unimportant, but because of the view that they make models of monetary economies analytically untractable. Recent studies that find that distributional effects of monetary policy are quantitatively important include Doepke and Schneider (2006) and Coibion, Gorodnichenko, Kueng and Silvia (2012).

${ }^{2}$ Lagos and Wright (2005, p.467) do introduce an upper bound on hours of work, $\bar{H}$, but they restrict their attention to equilibria where $H \leq \bar{H}$ does not bind and they do not characterize policy and value functions for values of the state variable when the constraint binds. Our key departure is to explicitly consider situations in which this constraint binds. Randy Wright argues that we are introducing a second change relative to the Lagos-Wright model by not allowing intertemporal trades across centralized markets. Our view is that the frictions that prevent such intertemporal trades-lack of commitment and the absence of public monitoring - are the same frictions that shut down credit in the decentralized market. Lending and borrowing across centralized markets would require some form of monitoring and enforcement and would introduce new securities that could potentially serve as means of payment in decentralized markets.
} 
Third, the buyer's disutility of work in the centralized market is linear, which generates a simple policy rule for the accumulation of real balances and simplifies out-of-steady-state dynamics. ${ }^{3}$

We first characterize steady-state equilibria and show that buyers have a constant target for their real balances, which represents their desired level of self-insurance. This target increases with their degree of patience and the frequency of trading opportunities in the decentralized goods market. If their labor endowment, $\bar{h}$, is sufficiently large, agents can reach this target in a single period and the distribution of real balances across buyers at the beginning of each period is degenerate. This special case is the one the literature has been focusing on. In contrast, if $\bar{h}$ is sufficiently small, then it takes $N \geq 2$ periods, where $N$ is endogenous, for an agent to reach his targeted real balances. As a result, the distribution of money holdings is non-degenerate and risk-sharing considerations matter. Provided that the length of a period of time is sufficiently small, ex-post heterogeneity with $N \geq 2$ is a generic property of equilibrium. As a benchmark, we calibrate the model using yearly data for the aggregate money demand. Parameter values are such that $N=1$, as in Lagos and Wright (2005). However, if we adjust the parameter values to be consistent with a monthly frequency, then the equilibrium features $N=5$ and a nondegenerate distribution of money holdings.

For most of the paper we focus on a class of tractable equilibria where buyers deplete their money holdings in full whenever they are matched with a seller. Under such a trading pattern the distribution of real balances is a truncated geometric distribution with $N \in \mathbb{N}$ mass points. This heterogeneity in wealth generates a distribution of consumption levels and prices across matches, with both output levels and prices being higher for richer buyers. Equilibria where buyers do not deplete their money holdings in full in a match are not solvable in closed form, but they can easily be solved numerically due to the recursive structure of the equilibrium.

We then study the transitional dynamics for allocations and prices following a one-time money injection through lump-sum transfer to buyers in the centralized market. ${ }^{4}$ If agents can reach their targeted real balances in a single period, $N=1$, as in the Lagos-Wright model, such a money injection has no real effect since the price level adjusts proportionally to the money supply and the economy instantly returns to its steady state. However, if $N \geq 2$ then our model features non-trivial transitional dynamics. We start the economy at a steady-state equilibrium where the distribution of money holdings has two mass points at the beginning of the period, $N=2$. A one-time increase in the money supply raises aggregate real balances, i.e., the price level does not increase as much as the money supply. The economy returns to its steady state in the following centralized market, i.e., the transition only lasts one period.

The reason the value of money fails to instantly reach its new steady-state value is because the centralized market cannot reshuffle the units of money among buyers in a way that preserves neutrality. Indeed, in the laissez-faire equilibrium buyers entering the competitive market with no money are constrained by their labor endowment and cannot reach their desired real balances in a single period. Hence, if they receive a lump-sum transfer, they will hold onto it in order to increase their real balances toward their target, which prevents

\footnotetext{
${ }^{3}$ The model remains tractable under general preferences, as shown in Rocheteau, Weill, and Wong (2015).

${ }^{4}$ We also consider other forms of transfers, including lump-sum transfers to both buyers and sellers.
} 
an instant return of the distribution to its steady state. By market clearing, the anticipated rate of return of money following the money injection is negative, which drives the target for real balances down. The distribution of real balances becomes less dispersed in the following decentralized goods market, which raises aggregate output if the seller's production cost is strictly convex and leads to higher welfare by providing risk sharing.

We provide conditions under which the injection of money triggers a deflation in the short run - the value of money rises above its initial steady-state value - and aggregate output increases. Symmetrically, a contraction of the money supply can generate an increase in the price level in the short run, thereby explaining the "price puzzle" of Eichenbaum (1992). Sufficiently large money injections are always inflationary in both the short and long run, and they make the distribution of money holdings degenerate in the short run.

If the initial steady state features a richer heterogeneity, at least three mass points in the distribution of real balances, $N \geq 3$, then the real effects of a one-time money injection are long-lasting. We illustrate this result by considering a 5 percent increase in the money supply for the same calibration as in Lagos and Wright (2005). At a yearly frequency the model features $N=1$ and such a shock instantly generates a 5 percent inflation. At a weekly frequency the equilibrium features $N=17$ (it takes 17 weeks for buyers to reach their targeted real balances) and the (annualized) inflation peaks initially at about $0.4 \%$ and it is persistent.

Finally, we extend the model to incorporate idiosyncratic unemployment risk in addition to the random

matching risk in the goods market. Formally, $\bar{h}$ follows a two-state Markov chain where the low state is interpreted as unemployment. We study a simple class of equilibria where unemployed agents need multiple periods in order to accumulate their targeted real balances and we show that the response of the economy to a monetary shock depends on the size of the unemployment rate. We also study repeated money injections leading to a constant money growth rate. An increase in the money growth rate reduces the rate of return of money, but it also improves risk-sharing by raising the real balances of the poorest, unemployed agents. Under some conditions on the steady-state unemployment rate and the income of the unemployed, the positive risk-sharing effect dominates and social welfare increases.

\subsection{Literature review}

Diamond and Yellin (1990) were the first to study non-degenerate distributions of money holdings analytically in a search environment, but their model was not explicit about the frictions that make money essentialmoney was introduced through a cash-in-advance constraint. Search-theoretic models of Shi (1995) and Trejos and Wright (1995) added heterogeneity and frictions (lack of commitment/enforcement, no monitoring) to make money essential, but the models were kept tractable by restricting money holdings to $\{0,1\}$. The model was extended by Camera and Corbae (1999) to allow for a more general support for the distribution of money holdings, and it was solved numerically by Molico (2006) under the assumption that buyers make take-it-or-leave-it offers to sellers. Zhu (2005) provides an existence result for monetary steady states. Green and Zhou (1998) and Zhou (1999) study a similar environment where goods are indivisible and prices are 
posted by sellers. They characterize analytically a class of equilibria where all transactions occur at the same price and show that there exists a continuum of such equilibria. In contrast, our model delivers a unique laissez-faire equilibrium.

Menzio, Shi, and Sun (2013) consider an environment with directed search and posted prices where firms produce divisible goods and individuals choose to be either buyers or workers in a period. ${ }^{5}$ They show that the laissez-faire monetary steady state is block-recursive in the sense that policy functions and value functions are independent of the distribution of real balances. In contrast we use the Lagos-Wright model with alternating market structures - random search and ex-post bargaining followed by price taking - and its version with ex-ante heterogeneity from Lagos and Rocheteau (2005) and Rocheteau and Wright (2005). We achieve a higher level of tractability by being able to solve for distributions and value functions in closed form, and by characterizing the equilibrium analytically both at and out of the steady state. In Menzio-Shi-Sun, agents' problems are not concave and the existence of equilibrium requires the use of monotone comparative statics methods. In contrast, all individual problems in our model are concave, and we can use textbook dynamic programming techniques to establish general properties of value and policy functions. Also, the bargaining game in the decentralized market could easily be replaced by price taking or competitive search, as in Rocheteau and Wright (2005). Finally, Sun (2012) extends Rocheteau and Wright's (2005) quasi-linear competitive search environment by introducing idiosyncratic shocks on the linear disutility of labor. While the model generates ex-post heterogeneity, the distribution for real balances conditional on the marginal disutility of labor is degenerate.

Closer to our approach, Chiu and Molico (2010, 2011) adopt the alternating-market structure of Lagos and Wright (2005). They relax the assumption of quasi-linear preferences in order to obtain distributional effects. While the results in Chiu and Molico are numerical, we obtain a tractable model with closed-form solutions. The main two differences between our approach and the one in Chiu and Molico are as follows. First, we assume ex ante heterogeneity between buyers and sellers as in LRW. As a result, the only relevant distribution of money holdings is the one across buyers, and this distribution affects the buyer's problem only through its first moment. Second, we adopt the fully linear specification for preferences over the centralized market good, again as in LRW, but we add an upper bound on the labor supply. This specification implies that buyers supply their full endowment of labor until they reach their targeted real balances. Moreover, it allows us to have the LRW model with a degenerate distribution and linear value function as a particular case. Zhu (2008) constructs a model with alternating market structures and general preferences and achieves tractability by assuming that agents from overlapping generations can trade at most once in the decentralized market with search and bargaining.

This model is related to our earlier work in Rocheteau, Weill, and Wong (2015) with important differences. The former describes a competitive economy in continuous time populated with ex-ante identical agents, where the idiosyncratic uncertainty takes the form of preference shocks for lumpy consumption. In contrast,

\footnotetext{
${ }^{5}$ Monetary models with divisible goods and directed search were first introduced by Rocheteau and Wright (2005) and Lagos and Rocheteau (2005).
} 
we study a discrete-time economy with search and bargaining, where ex-ante heterogenous agents face idiosyncratic uncertainty due to random matching. These ingredients make our model more easily comparable to the New-Monetarist framework. Moreover, the use of discrete time allows us to harness the ex-post heterogeneity, thereby facilitating the study of transitional dynamics, a main focus of our paper. We also assume that $\bar{h}$ is stochastic in order to study the positive and normative effects of inflation when there is employment risk.

Berentsen, Camera, and Waller (2005) generalize the Lagos-Wright model by assuming two rounds of trade before agents can readjust their money holdings. This assumption generates a non-degenerate distribution of money holdings at the start of the second decentralized market. In contrast to our environment, any money injection in the centralized market is neutral. Yet, our model generates a rich distribution of money holdings with a single round of pairwise meetings - the distribution can have any number of mass points as well as continuous intervals. Williamson (2006) obtains short-run non-neutralities in the Lagos-Wright model by introducing limited participation, while Faig and Li (2009) achieve a similar objective by adopting the Lucas signal extraction problem. In our model all agents can participate in the centralized market in all periods, and changes in the money supply are common knowledge.

Wallace (1997) considers an unanticipated change of the money supply in a random matching model with $\{0,1\}$ money holdings and shows that the short-run effects are predominantly real while the long-run effects are predominantly nominal. Jin and Zhu (2014) generalize the model by assuming a large upper bound on money holdings and by allowing lotteries to overcome the indivisibility of money. They show, through numerical examples, that a money injection can have a persistent effect on output and price adjustments are sluggish. Chiu and Molico (2014) study a closely related model with divisible money and no upper bound on money holdings - as in our setting - and show numerically that unanticipated inflation shocks can have persistent effects on output, prices, and welfare.

Finally, Scheinkman and Weiss (1986), in the context of a Bewley economy with competitive markets and aggregate endowment shocks, show that one-time money injections generate output and price effects which depend on the state of the economy. Similarly, Algan, Challe, and Ragot (2011) study temporary and permanent changes in money growth in a Bewley economy with idiosyncratic employment shocks and quasi-linear preferences, focusing on equilibria with two-state wealth distribution. In contrast, our economy has two sectors and features an idiosyncratic consumption risk due to the assumption that some trades take place under random, pairwise matching and bargaining. In the last part of the paper we combine both random matching risk and unemployment risk in order to investigate how short-run non-neutralities and the optimal inflation rate depend on the unemployment rate.

\section{Environment}

Time, $t \in \mathbb{N}_{0}$, is discrete and the horizon infinite. Each period has two stages. In the first stage, agents trade in a decentralized market (DM) with pairwise meetings and bargaining. In the second stage, they trade in 
a centralized market $(\mathrm{CM})$. The $\mathrm{DM}$ and $\mathrm{CM}$ consumption goods are perishable and the CM good is taken as the numéraire.

The economy is populated by two types of agents: a unit measure of buyers and a measure $\sigma$ of sellers, refering to an agent's role in the DM. In the first stage buyers want to consume but cannot produce, while sellers are able to produce but do not wish to consume. The period-utility function of a buyer is

$$
u(y)+c-h,
$$

where $y \in \mathbb{R}_{+}$is DM consumption, $c$ is CM consumption, and $h$ is CM labor supply. We assume that $u$ is bounded, and strictly concave with $u(0)=0, u^{\prime}(0)=\infty$, and $u^{\prime}(+\infty)=0$. In order to apply dynamic programming techniques with bounded returns we assume that $c$ is bounded above by a satiation point, $\bar{c}>0 .{ }^{6}$ Throughout the analysis $\bar{c}$ is sufficiently large so that buyers never reach their satiation point along the equilibrium path, and $\bar{c}$ does not affect equilibrium outcomes. The technology to produce the CM good is linear so that $h$ units of labor generate $h$ units of numéraire. The buyer's endowment of labor is $\bar{h}$. $(\bar{h}$ is stochastic in Section 6). In contrast to the existing literature, we consider equilibria where the feasibility constraint, $h \leq \bar{h}$, binds for some agents, thereby departing from a quasi-linear environment with degenerate distributions of money holdings. The period-utility function of a seller is

$$
-v(y)+c
$$

where $v(y)$ is the disutility of producing $y$ units of the DM good in a pairwise meeting and $c \geq 0$ is the linear utility of consuming the numéraire. We do not impose a satiation point for sellers' consumption. The discount factor across periods, $\beta \in(0,1)$, is common to all agents.

Market structures differ in the DM and CM. In the DM a measure $\alpha \leq \min \{1, \sigma\}$ of bilateral matches composed of one buyer and one seller is formed. The trading mechanism is such that the buyer in a match makes a take-it-or-leave-it offer to the seller. In the CM all agents are price-takers and markets clear.

Intertemporal gains from trade exist when the seller produces $y$ in the DM in exchange for $c$ in the CM with $v(y) \leq c \leq u(y)$. However, these gains from trade cannot be exploited with unsecured credit since buyers cannot commit to repay their debt and there is no monitoring. There is an intrinsically useless, perfectly divisible and storable asset called money that agents can (but don't have to) use as a medium of exchange to overcome these frictions. We use $M$ to denote the constant money supply in the DM. The CM price of money in terms of the numéraire is $\phi_{t}$. The gross rate of return of money is denoted $R_{t} \equiv \phi_{t} / \phi_{t-1}$.

\section{Full insurance}

Suppose that buyers can commit to an insurance contract according to which they supply $h$ units of labor every period in exchange for a consumption level $y$ in the (observable) event they are matched in the DM. The expected utility of the buyer in each period is $\alpha u(y)-h$. The total CM output produced by buyers, $h$, is promised to the $\alpha$ sellers who are matched in the DM, $c=h / \alpha$. We keep a similar trading mechanism

\footnotetext{
${ }^{6}$ In the appendix, we study the dynamic programming problem with the utility function written explicitly as $\min (c, \bar{c})$.
} 
to the one described above: buyers make take-it-or-leave-it offers to sellers. Sellers are willing to go along with the proposed allocation if $c \geq v(y)$, i.e., their consumption is greater than their disutility of production. Hence, the optimal insurance contract among buyers, $\left(h^{F I}, y^{F I}\right)$, solves:

$$
\max _{y, c, h \leq \bar{h}}[\alpha u(y)-h] \quad \text { s.t. } \quad c=\frac{h}{\alpha} \geq v(y) .
$$

The solution is $y^{F I}=\hat{y}$ and $h^{F I}=\alpha v(\hat{y})$, where $u^{\prime}(\hat{y})=v^{\prime}(\hat{y})$, if $\bar{h} \geq \alpha v(\hat{y})$. Otherwise, $y^{F I}=v^{-1}(\bar{h} / \alpha)<\hat{y}$ and $h^{F I}=\bar{h}$. So provided that labor endowments are sufficiently large, the full-insurance allocation equalizes the marginal utility of consumption of the buyer and the marginal disutility of the seller, as in LRW. In contrast, if the labor endowment is not large enough to implement $\hat{y}$ then the full-insurance allocation is such that DM output is maximum, $h^{F I}=\bar{h}$, and $u^{\prime}\left(y^{F I}\right)>v^{\prime}\left(y^{F I}\right)$.

\section{Equilibrium}

We characterize an equilibrium in three steps. First, we study the decision problem of a buyer who takes as given the sequence of rates of return, $\left\{R_{t}\right\}_{t=1}^{+\infty}$. Second, given the buyer's optimal consumption/saving decisions we write the law of motion for the distribution of real balances. Third, we clear the money market in every CM in order to obtain the value of money, $\left\{\phi_{t}\right\}_{t=0}^{+\infty}$, and hence its rate of return.

Value functions Consider first the problem of a buyer at the beginning of the CM of period $t$ holding $z$ real balances (money balances expressed in terms of the period- $t$ CM good). In order to characterize this problem we make two assumptions on the path for the gross rate of return of fiat money, $\left\{R_{t+1}\right\}_{t=0}^{+\infty}$. First, there exists some $\underline{R}>0$ such that, for all $t \geq 0, R_{t+1}>\underline{R}$. This first assumption rules out hyper-inflationary dynamics such that the gross rate of money approaches 0 . Second, we assume the following condition holds:

$$
\sum_{i=1}^{\infty} \beta^{i}(1-\alpha)^{i-1} \alpha \prod_{j=1}^{i} R_{j}<\infty
$$

The second assumption is used to establish that the expected present marginal value of real balances is finite, which in turn allows us to prove the differentiability of the value function. Note that both assumptions are verified for the steady states and transitional dynamics we analyze in the paper, whereby $R_{t} \rightarrow 1$ as $t \rightarrow \infty$.

The value function of a buyer solves:

$$
\begin{gathered}
W_{t}(z)=\max _{h, z^{\prime}}\left\{c-h+\beta V_{t+1}\left(z^{\prime}\right)\right\} \\
\text { s.t. } z^{\prime}=R_{t+1}(h-c+z) \geq 0, \quad h \in[0, \bar{h}], \quad c \in[0, \bar{c}] .
\end{gathered}
$$

According to (4) the buyer chooses his consumption, $c$, labor supply, $h$, and next-period real balances, $z^{\prime}$, in order to maximize his discounted continuation value in $t+1$ net of the disutility of work. The budget identity, (5), specifies that the next-period real balances are equal to the sum of the current wealth and savings (labor income net of consumption) multiplied by the gross rate of return of money. Moreover, the buyer's problem is subject to a non-negativity constraint for real balances, a feasibility constraint on labor 
supply, and an optimality condition that specifies that consumption cannot be larger than its satiation point. The value functions are indexed by $t$ as the gross rate of return of money, $R_{t}$, might vary over time.

In the DM each matched buyer makes a take-it-or-leave-it offer, $(y, p)$, to a seller, where $y$ is the DM output to be produced by the seller in exchange for a payment, $p$, in the form of real balances. ${ }^{7}$ This payment must satisfy the feasibility constraint $p \leq z$ since buyers' IOUs are not accepted by sellers due to lack of both commitment and monitoring. It must also satisfy the individual rationality constraint of the seller according to which the payment must be at least equal to the disutility of production, $-v(y)+p \geq 0$. When writing this participation constraint we anticipated on the result that sellers spend all the money they accumulate in the DM in the following CM. Indeed, sellers get no surplus in the DM and hence they have no motive for carrying real balances from one period to the next. The seller's participation constraint will hold at equality, $v(y)=p$, as otherwise the buyer would have an incentive to reduce the size of the payment for the same output level. Hence, the lifetime expected discounted utility of a buyer at the beginning of the DM is:

$$
V_{t}(z)=\alpha \max _{p \leq z}\left[\omega(p)+W_{t}(z-p)\right]+(1-\alpha) W_{t}(z)
$$

where $\omega(p) \equiv u \circ v^{-1}(p)$. With probability $\alpha$ the buyer is matched in the DM, in which case he chooses an output level, $y$, in exchange for $p=v(y)$ units of real balances. With probability $1-\alpha$ the buyer is unmatched and enters the next CM with $z$ real balances.

We now prove the existence, continuity, and differentiability of the value functions, $V_{t}(z)$ and $W_{t}(z)$. From (4)-(5) and (6) we define $W_{t}$ recursively as follows:

$$
\begin{gathered}
W_{t}(z)=\max _{p, z^{\prime}}\left\{z-\frac{z^{\prime}}{R_{t+1}}+\beta \alpha\left[\omega(p)+W_{t+1}\left(z^{\prime}-p\right)\right]+\beta(1-\alpha) W_{t+1}\left(z^{\prime}\right)\right\} \\
\text { s.t. } z^{\prime} \in\left[R_{t+1}(z-\bar{c}), R_{t+1}(z+\bar{h})\right] \text { and } p \leq z^{\prime} .
\end{gathered}
$$

Proposition 1 The Bellman equations (6)-(7) have unique bounded solutions, $V_{t}(z)$ and $W_{t}(z)$. The functions $V_{t}(z)$ and $W_{t}(z)$ are continuous, concave, strictly increasing, and satisfy

$$
\|W\| \leq \frac{\bar{c}+\bar{h}+\beta \alpha\|\omega\|}{1-\beta} \text { and }\|V\| \leq \frac{\bar{c}+\bar{h}+\alpha\|\omega\|}{1-\beta} .
$$

Moreover, $W_{t}$ and $V_{t}$ are continuously differentiable with $W_{t}^{\prime}\left(0^{+}\right)<\infty$ and $V_{t}^{\prime}\left(0^{+}\right)=\infty$.

In order to prove Proposition 1 we use (7) to define a contraction mapping from the set of bounded functions defined over $\mathbb{N} \times \mathbb{R}_{+}$into itself. As a result the fixed point of this functional equation is continuous and bounded. Moreover, concavity is preserved by this mapping according to Theorem 4.7 in Stokey and Lucas (1989). The main difficulty we confront in order to establish differentiability is that the Envelope Theorem of Benveniste and Scheinkman, which requires that the optimal choice lies in the interior of the constraint set, does not apply to our environment since the labor endowment constraint may bind. To

\footnotetext{
${ }^{7}$ The model remains tractable under competitive pricing. See Rocheteau, Weill, and, Wong (2015) for a related model in continuous-time where households trade in a competitive market.
} 
address this difficulty, Rincón-Zapatero and Santos (2009) have established an envelope theorem for a broad class of stationary dynamic optimization problems in which optimal choices may not lie in the interior of the constraint set, but must lie in the interior of the state space. We apply their results to our environment. The application is not immediate, however, because two of their maintained assumptions are violated. First, our environment is non-stationary, since $R_{t+1}$ is not constant over time. Second, some optimal choices may not lie in the interior of the state space: namely, when a buyer chooses to deplete his money holdings in full in the DM, he enters the following CM with zero money balances.

Choice of real balances In the following we focus on equilibria such that the condition, $c \leq \bar{c}$, never binds for $z$ in the support of the money distribution. Let $\xi_{t}(z)$ denote the Lagrange multiplier associated with $h \leq \bar{h}$. Substituting $h=z^{\prime} / R_{t+1}-z$ from (5) into the objective, we can rewrite the buyer's problem as:

$$
W_{t}(z)=z+R_{t+1}^{-1} \max _{z^{\prime} \geq 0}\left\{-z^{\prime}+\beta R_{t+1} V_{t+1}\left(z^{\prime}\right)+\xi_{t}\left[R_{t+1}(\bar{h}+z)-z^{\prime}\right]\right\} .
$$

If $\xi_{t}=0$, then the second term on the right side of (8) is independent of $z$, the choice of next-period real balances is independent of current wealth, and $W_{t}$ is linear, as in Lagos and Rocheteau (2005, Eq. (9)). However, if the feasibility constraint on labor binds, $\xi_{t}>0$, then the choice of real balances is no longer independent of current wealth and $W_{t}$ is no longer linear - the two key ingredients of the tractability of the Lagos-Wright model. The envelope theorem applied to (8) gives:

$$
W_{t}^{\prime}(z) \equiv \lambda_{t}(z)=1+\xi_{t}
$$

The first-order condition for the choice of real balances is

$$
-\lambda_{t}(z)+R_{t+1} \beta V_{t+1}^{\prime}\left(z^{\prime}\right) \leq 0, \quad \text { " }=\text { if } z^{\prime}>0,
$$

where $\lambda_{t}=1+\xi_{t}$ measures the cost of accumulating real balances, and $R_{t+1} \beta V_{t+1}^{\prime}\left(z^{\prime}\right)$ is the marginal benefit of real balances in the CM of period $t$ : the discounted marginal value of real balances in the DM of $t+1$ times the gross rate of return of real balances. We define a buyer's targeted real balances for $t+1, z_{t+1}^{\star}$, as a solution to (10) when $\xi_{t}=0$, i.e.,

$$
R_{t+1} \beta V_{t+1}^{\prime}\left(z_{t+1}^{\star}\right)=1
$$

The target is the buyer's choice when $h \leq \bar{h}$ does not bind, $z+\bar{h} \geq z_{t+1}^{\star} / R_{t+1}$. It equalizes the marginal disutility of labor, one, with the discounted marginal value of real balances in the next DM. We show in the Appendix that the set of solutions to (11), denoted $Z_{t+1}^{\star}$, is convex, bounded above, and bounded away from zero. We will proceed in the following under the presumption that $Z_{t+1}^{\star}$ is a singleton, which is the relevant case in the rest of our analysis. (The proofs in the Appendix do not rely on this simplification.)

Let us turn briefly to the seller's choice of real balances in the CM. Since sellers do not get any surplus in the DM their problem is simply:

$$
W_{t}^{s}(z)=\max _{c, z^{\prime}}\left\{c+\beta W_{t+1}^{s}\left(z^{\prime}\right)\right\} \quad \text { s.t. } \quad z^{\prime}=R_{t+1}(z-c) .
$$

Hence, $W_{t}^{s}(z)$ is linear in $z$ and $z^{\prime}=0$ provided that $\beta R_{t+1}<1$. 
Terms of trade in the DM. The solution to the maximization problem on the right side of $(6)$ is $p=v(y)$ and

$$
\begin{aligned}
\omega^{\prime}(p) & =W_{t}^{\prime}(z-p) \text { if } \omega^{\prime}(z)<W_{t}^{\prime}(0) \\
p & =z \text { otherwise. }
\end{aligned}
$$

According to (12) the buyer equalizes his marginal utility from spending a unit of real balances in the DM, $u^{\prime}(y) / v^{\prime}(y)$, with the marginal value of real balances in the CM as measured by $W_{t}^{\prime}$. We represent (12) in Figure 1: the left side is the blue downward-sloping curve and the right side is the red upward-sloping curve. From the (weak) concavity of $W$ it follows that $W_{t}^{\prime}(z-p)$ is non-increasing in $z$. Hence, as $z$ increases the red upward-sloping curve moves downward, illustrated by the two dashed curves located underneath the plain upward-sloping curve. Those curves are horizontal for low values of $p$ because the buyer enters the next CM with enough real balances to reach his target, in which case the marginal utility of real balances is equal to one. It follows that payment, $p$, and output, $y$, are non-decreasing in the buyer's real balances. Similarly, if we denote post-trade real balances by $\tilde{z}=z-p$ then $\omega^{\prime}(z-\tilde{z})=W_{t}^{\prime}(\tilde{z})$. Hence, post-trade real balances are weakly increasing in pre-trade real balances.

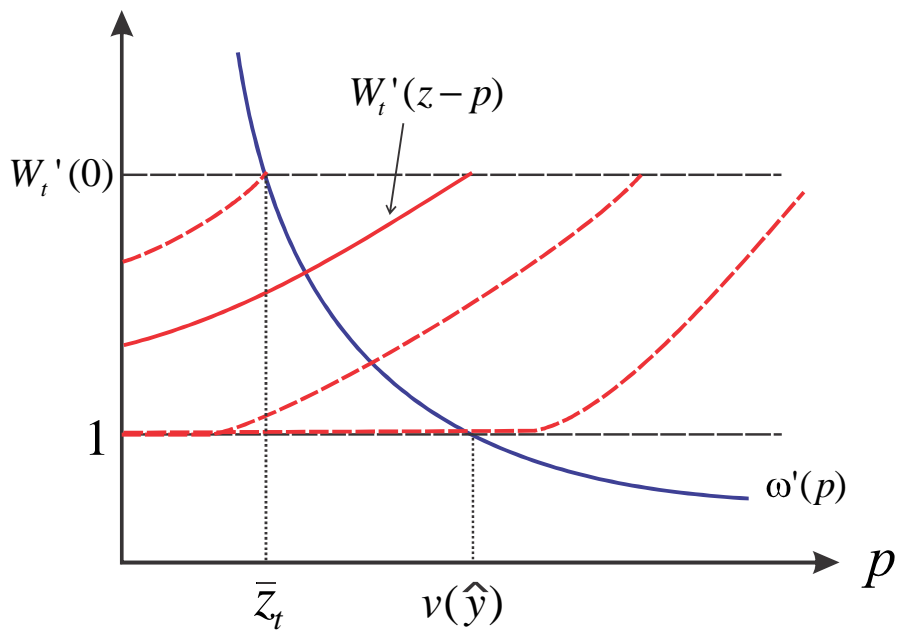

Figure 1: Bargaining outcome

From (13), if the marginal utility from spending real balances in the DM is larger than the marginal value of money in the CM when money holdings are depleted in full, $\omega^{\prime}(z) \geq W_{t}^{\prime}(0)$, then the buyer spends all his real balances. We denote by $\bar{z}_{t}$ the threshold below which there is full depletion of real balances. It solves

$$
\omega^{\prime}\left(\bar{z}_{t}\right)=W_{t}^{\prime}(0)
$$

We have established in Proposition 1 that $W_{t}^{\prime}(0)<+\infty$, the marginal value of real balances of a buyer entering the CM with no money is finite. Given that $\omega^{\prime}(0)=\infty$ it follows that $\bar{z}_{t}>0$, i.e., there is an interval of real balances for which buyers find it optimal to spend all their real balances in a DM match. 


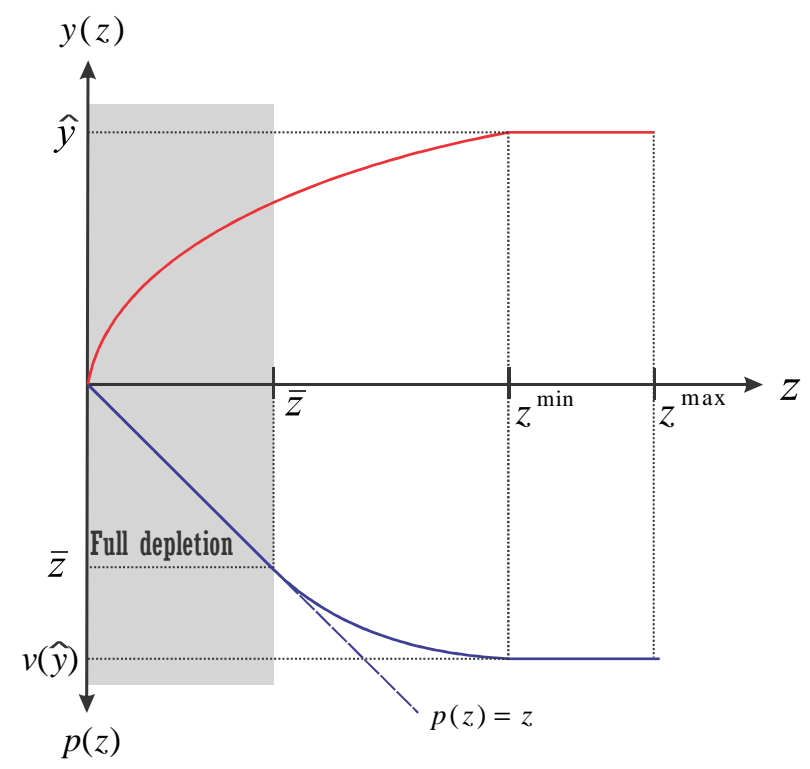

Figure 2: Terms of trade in DM pairwise meetings

In Figure 1 we represent $W^{\prime}\left(\bar{z}_{t}-p\right)$ by a dashed curve located above the plain upward-sloping curve. It intersects the horizontal line given by $W_{t}^{\prime}(0)$ and $\omega^{\prime}(p)$ when $p=\bar{z}_{t}$.

There are two thresholds for real balances, $z_{t}^{\min }$ and $z_{t}^{\max }$, such that for all $z \in\left(z_{t}^{\min }, z_{t}^{\max }\right)$ buyers anticipate that they will be able to reach their target in the following CM after consuming $p(z)$ in the current DM. Because agents can reach their target, their post-trade real balances must satisfy $W_{t}^{\prime}\left[z-p_{t}(z)\right]=1$ so that, from (12), $y=\hat{y}$ and $p=v(\hat{y})$. Hence, the thresholds must be given by:

$$
\begin{aligned}
& z_{t}^{\min }=v(\hat{y})+\frac{z_{t+1}^{\star}}{R_{t+1}}-\bar{h} \\
& z_{t}^{\max }=v(\hat{y})+\frac{z_{t+1}^{\star}}{R_{t+1}}+\bar{c} .
\end{aligned}
$$

According to (15) in order to be unconstrained by his labor endowment in the following CM the buyer must hold at least $z_{t}^{\min }$ so that after spending $v(\hat{y})$ in the DM he can reach his target by working $\bar{h}$. Equation (16) has a similar interpretation.

In contrast to the bargaining outcome in the LRW model, if $\bar{h}<z_{t+1}^{\star} / R_{t+1}$ then there is an interval of real balances, $\left(\bar{z}_{t}, z_{t}^{\mathrm{min}}\right)$, for which buyers spend a fraction of their real balances even though they consume less than $\hat{y}$. Buyers find it optimal not to spend all their real balances because they anticipate that they will not be able to reach their targeted real balances in the following CM and hence, according to (12), they equalize the marginal value of real balances in the DM, $\omega^{\prime}(p)$, and the marginal value of real balances in the $\mathrm{CM}, W_{t}^{\prime}(z-p)>1$. We summarize the outcome of the bargaining problem in the following proposition and Figure 2.

Proposition 2 (Bargaining outcome) The buyer's problem in the DM, (6), has a unique solution, $p_{t}(z)$. This solution is continuous, increasing, and satisfies $\lim _{z \rightarrow 0} p_{t}(z)=0$ and $\lim _{z \rightarrow \infty} p_{t}(z)=\infty$. Assume 
$W_{t}^{\prime}(0)>1$, i.e., $\bar{h}<z_{t+1}^{\star} / R_{t+1}$. There exist $\bar{z}_{t}<z_{t}^{\min }<z_{t}^{\max }$ defined in (14), (15), and (16), such that:

1. For all $z \leq \bar{z}_{t}, p_{t}(z)=z$ and $y_{t}(z)=v^{-1}(z)$.

2. For all $z \in\left(\bar{z}_{t}, z_{t}^{\min }\right), p_{t}(z)<z$, and $y_{t}(z)=v^{-1}\left[p_{t}(z)\right]$ are increasing in real balances.

3. For all $z \in\left[z_{t}^{\min }, z_{t}^{\max }\right], p_{t}(z)=v(\hat{y})$, and $y_{t}(z)=\hat{y}$.

The marginal value of real balances at the beginning of the DM is

$$
V_{t}^{\prime}(z)=\alpha \omega^{\prime}\left[p_{t}(z)\right]+(1-\alpha) \lambda_{t}(z)
$$

where $p_{t}(z)$ is the solution to the bargaining problem, (12)-(13). The marginal value of real balances in the DM is equal to the marginal utility of DM consumption with probability $\alpha$ (a match occurs) and the marginal utility of real balances in the following CM with probability $1-\alpha$ (the buyer is unmatched). We substitute $V_{t+1}^{\prime}\left(z^{\prime}\right)$ by its expression given by (17) into (10) to obtain the law of motion for the marginal value of real balances:

$$
\lambda_{t}(z)=R_{t+1} \beta\left\{\alpha \omega^{\prime}\left[p_{t+1}\left(z^{\prime}\right)\right]+(1-\alpha) \lambda_{t+1}\left(z^{\prime}\right)\right\} .
$$

The marginal value of real balances at time $t$ is equal to the discounted marginal value of $R_{t+1}$ real balances in $t+1$ plus the present value of a liquidity term equal to $\alpha\left\{\omega^{\prime}\left[p_{t+1}\left(z^{\prime}\right)\right]-\lambda_{t+1}\left(z^{\prime}\right)\right\}$ which corresponds to the buyer's expected marginal surplus from spending a unit of real balances in a DM match. Iterating (18) forward we obtain a closed-form solution for the derivative of the value function:

$$
\lambda_{t}(z)=\sum_{i=1}^{\infty} \beta^{i}(1-\alpha)^{i-1} \alpha\left(\prod_{j=1}^{i} R_{t+j}\right) \omega^{\prime}\left[p_{t+i}\left(z_{t+i}\right)\right],
$$

where $z_{t+i}$ is a sequence of optimal real balances starting from $z_{t}=z$.

Distribution of real balances. Let us turn to the law of motion for the distribution of real balances. We denote as $F_{t}(z)$ the distribution of real balances at the beginning of period $t$. The distribution at time $t+1$ is given by:

$$
F_{t+1}(z)=\int \alpha \mathbb{I}_{\left\{z_{t+1}\left[x-p_{t}(x)\right] \leq z\right\}}+(1-\alpha) \mathbb{I}_{\left\{z_{t+1}(x) \leq z\right\}} d F_{t}(x),
$$

where $z_{t+1}(x)$ is the policy function derived from (12)-(13) that specifies the choice of real balances in $t+1$, given the real balances at the beginning of the $\mathrm{CM}$ in $t$. It is given by:

$$
z_{t+1}(x)=\min \left\{(x+\bar{h}) R_{t+1}, z_{t+1}^{\star}\right\}
$$

where we assume that the satiation point does not bind over the support of the distribution of real balances (see appendix for the general case). Either the buyer can reach his target, $z_{t+1}^{\star}$, or he supplies all his labor so that his total wealth is composed of his initial wealth and his labor endowment, $x+\bar{h}$. This wealth is capitalized according to the gross real rate of return of fiat money. The first term underneath the integral on the right side of (20) represents the measure $\alpha$ of buyers who are matched in the DM and enter the CM with $x-p_{t}(x)$ real balances, where $x$ is their pre-trade real balances. In the CM they accumulate $z_{t+1}\left[x-p_{t}(x)\right]$ for period $t+1$. The second term represents the unmatched buyers. 
Value of money Finally, the value of money is determined by the following money market clearing condition:

$$
\phi_{t} M=\int x d F_{t}(x)
$$

Hence, the rate of return of money is

$$
R_{t+1}=\frac{\phi_{t+1}}{\phi_{t}}=\frac{\int x d F_{t+1}(x)}{\int x d F_{t}(x)} .
$$

Definition 1 Given some initial distribution, $F_{0}$, an equilibrium is a sequence, $\left\{F_{t}, \phi_{t}, R_{t+1}\right\}_{t=0}^{+\infty}$, that solves (20), (21), and (22).

A steady-state equilibrium is such that $\left\{F_{t}, \phi_{t}\right\}$ is constant over time and the gross rate of return of money is $R_{t}=\phi_{t+1} / \phi_{t}=1$. From (18) with $\xi\left(z^{\star}\right)=0$ the targeted real balances solve:

$$
\frac{u^{\prime}\left[y\left(z^{\star}\right)\right]}{v^{\prime}\left[y\left(z^{\star}\right)\right]}=1+\frac{r}{\alpha}
$$

where from (12)-(13), $y\left(z^{\star}\right)$ is the solution to

$$
\begin{aligned}
W^{\prime}\left[z^{\star}-v(\hat{y})\right] & =1+\frac{r}{\alpha} \text { if } \omega^{\prime}\left(z^{\star}\right)<W^{\prime}(0) \\
z^{\star} & =v(\hat{y}) \text { otherwise. }
\end{aligned}
$$

At the targeted real balances the ratio of the marginal utility of DM consumption to the marginal disutility of DM production is equal to the marginal disutility of labor in the CM, one, plus the average holding cost of real balances. This cost is equal to the rate of time preference multiplied by the average period length until a match in the DM occurs, $1 / \alpha$.

Given $z^{\star}$ we can define $Q\left(z,\left[0, z^{\prime}\right]\right)$ as the probability that a buyer with $z \in\left[0, z^{\star}\right]$ real balances at the beginning of period $t$ ends up with less than $z^{\prime}$ at the beginning of the following period, $t+1$. It solves:

$$
\begin{aligned}
Q\left(z,\left[0, z^{\prime}\right]\right) & =0 \text { if } z^{\prime}<\min \left\{z-p(z)+\bar{h}, z^{\star}\right\} \\
& =\alpha \text { if } z^{\prime} \in\left[\min \left\{z-p(z)+\bar{h}, z^{\star}\right\}, \min \left\{z+\bar{h}, z^{\star}\right\}\right) \\
& =1 \text { if } z^{\prime} \geq \min \left\{z+\bar{h}, z^{\star}\right\} .
\end{aligned}
$$

Since both $z$ and $z-p(z)$ are weakly increasing, the transition probability is monotone. It satisfies the Feller property since $z$ and $z-p(z)$ are continuous. ${ }^{8}$ It is also easy to verify the mixing property. ${ }^{9}$ Existence and uniqueness of a stationary distribution follows from Theorem 12.12 in Stokey and Lucas (1989).

\footnotetext{
${ }^{8}$ To see that it is satisfied, consider for any $z$ a continuity point of the $\operatorname{CDF} z^{\prime} \mapsto Q\left(z,\left[0, z^{\prime}\right]\right)$. That is, any $z^{\prime}$ different from the discontinuity point of the $\mathrm{CDF}$, which are $\min \left\{z-p(z)+\bar{h}, z^{\star}\right\}$ and $\min \left\{z+\bar{h}, z^{\star}\right\}$. Suppose for example that $z^{\prime}<\min \left\{z-p(z)+\bar{h}, z^{\star}\right\}$. Then, by continuity, for any sequence $z_{n} \rightarrow z, z^{\prime}<\min \left\{z_{n}-p\left(z_{n}\right)+\bar{h}, z^{\star}\right\}$ as long as $n$ is large enough. This implies that $Q\left(z_{n},\left[0, z^{\prime}\right]\right)=Q\left(z,\left[0, z^{\prime}\right]\right)$. The result follows from Theorem 12.8 in Stokey and Lucas (1989), together with point $\mathrm{b}$ in exercise 12.7 .

${ }^{9}$ To verify the mixing property of Assumption 12.1 in Stokey and Lucas (1989), we need to show that there exists some $c \in\left[0, z^{\star}\right]$, some $\varepsilon>0$ and some $N \geq 1$ such that $Q^{N}\left(0,\left[c, z^{\star}\right]\right) \geq \varepsilon$ and $Q^{N}\left(z^{\star},\left[0, z^{\star}\right]\right) \geq \varepsilon$. Let $c=z^{\star}$ and $N=\lfloor x\rfloor$, i.e., the number of period of production required to reach the target $z^{\star}$ starting from zero. Then the mixing property is verified for $\varepsilon=(1-\alpha)^{N}$.
} 


\section{Money in the long run}

We focus on equilibria where it takes $N>1$ consecutive rounds of CM trades for a buyer with depleted money holdings to rebuild his targeted real balances if he remains unmatched in all DMs. (The case $N=1$ is the LRW model.) Moreover, we will first focus on equilibria where buyers deplete all their real balances in the DM, $z^{\star}<\bar{z} .{ }^{10}$

Targeted real balances From (23), the buyer's targeted real balances, $z^{\star} \in((N-1) \bar{h}, N \bar{h}]$, solves

$$
\omega^{\prime}\left(z^{\star}\right)=1+\frac{r}{\alpha} .
$$

As buyers become more patient, or as the frequency of matches increases, the targeted real balances increase. The condition $z^{\star} \in((N-1) \bar{h}, N \bar{h}]$ can be reexpressed as

$$
(N-1) \bar{h}<\omega^{\prime-1}\left(1+\frac{r}{\alpha}\right) \leq N \bar{h}
$$

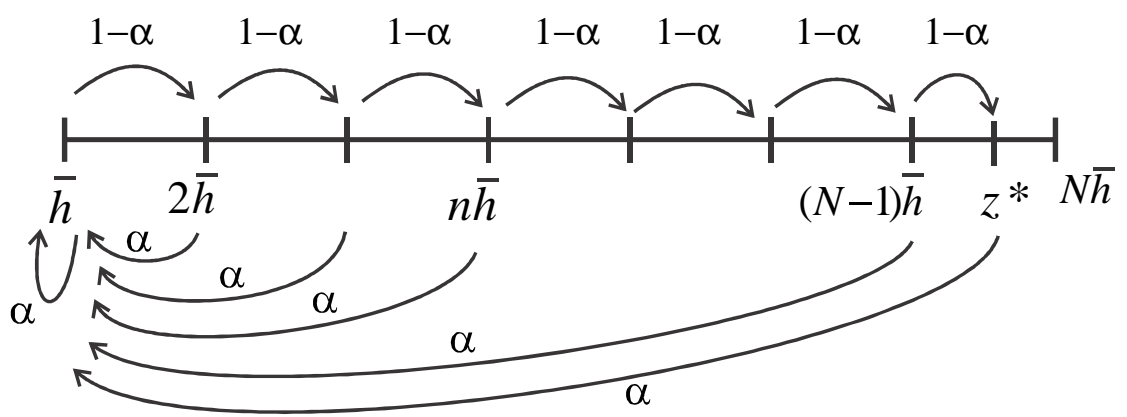

Figure 3: Support of the distribution of real balances

Distribution of real balances The support of the distribution of real balances across buyers at the beginning of a period is $\left\{\bar{h}, 2 \bar{h}, \ldots,(N-1) \bar{h}, z^{\star}\right\}$. As illustrated in Figure 3, buyers increase their real balances by the size of their labor endowment, $\bar{h}$, until they reach their target. The distribution $F$ is composed of $N$ mass points, $\left\{\mu_{n}\right\}_{n=1}^{N}$, where $\mu_{n}$ is the measure of buyers holdings $n \bar{h}$ for all $n \in\{1, \ldots, N-1\}$ and $\mu_{N}$ is the measure of buyers holding their target, $z^{\star}$. We have:

$$
\begin{aligned}
\mu_{1} & =\alpha \\
\mu_{n} & =(1-\alpha) \mu_{n-1} \text { for all } n \in\{2, N-1\} \\
\alpha \mu_{N} & =(1-\alpha) \mu_{N-1} .
\end{aligned}
$$

\footnotetext{
${ }^{10}$ The model is tractable numerically, even when the equilibrium features partial depletion, because it can be solved recursively. First, $W(z)$ is the fixed point of a contraction mapping, (7), that is independent of the distribution of real balances. Second, once $W(z)$ and the associated policy function, $p(z)$, are obtained (by iterations of the Bellman equation) we can use them to compute the distribution of real balances. Numerically, we generate a large number of long trading histories and we use the resulting terminal real balances to compute the empirical distribution of real balances. (The algorithm is detailed in the appendix.)
} 
According to (26) each buyer is matched with a seller with probability $\alpha$, in which case he spends all his real balances (since we are focusing on equilibria with full depletion). By the Law of Large Numbers the measure of buyers entering the CM with depleted money balances is $\alpha$. Those buyers supply their full endowment of labor in order to start the following period with $z_{1}=\bar{h}$ real balances. According to (27) the measure of agents holding $z_{n}=n \bar{h} \in\left(z_{1}, z^{\star}\right)$ is equal to the measure of buyers holding $z_{n-1}, \mu_{n-1}$, times the probability that they were unmatched in the last DM round, $1-\alpha$, so that such buyers add $\bar{h}$ to their existing real balances. Finally, the measure of agents holding the targeted real balances is determined such that the flow of buyers with the targeted real balances who are matched in the DM, $\alpha \mu_{N}$, is equal to the flow of buyers holding $z_{N-1}$ who are unmatched in the DM and reach $z^{\star}$ in the next CM. It is straightforward from (26)-(28) to solve for the distribution of real balances in closed form:

$$
\begin{aligned}
& \mu_{n}=\alpha(1-\alpha)^{n-1} \text { for all } n=1, \ldots, N-1 \\
& \mu_{N}=(1-\alpha)^{N-1} .
\end{aligned}
$$

From (29)-(30) the distribution of real balances is a truncated geometric distribution. ${ }^{11}$

As a result of the ex-post heterogeneity across buyers, and because terms of trade are determined through bargaining, the model features a distribution of nominal prices in the DM. The unit price of the DM output for a buyer holding $z_{n}=n \bar{h}$ real balances is $z_{n} / v^{-1}\left(z_{n}\right) \phi$, which is increasing in $z_{n}$ if $v$ is strictly convex. Thus, the richest agents in the DM purchase larger quantities and pay a higher price to compensate sellers for their convex disutility of production. The fraction of the transactions taking place at that price is $\mu_{n}$.

Value of money and prices. Aggregate real balances are $\phi M=\sum_{n=1}^{N} \mu_{n} z_{n}$. From (29)-(30), and after some calculation, this gives

$$
\phi M=\bar{h} \frac{\left\{1-(1-\alpha)^{N-1}[(N-1) \alpha+1]\right\}}{\alpha}+(1-\alpha)^{N-1} z^{\star}
$$

Aggregate real balances do not depend on the nominal money supply and hence money is neutral in the long run. For a given $N$ the value of money increases with the buyer's labor endowment, $\bar{h}$, and it decreases with the rate of time preference, $r$.

Marginal value of real balances Next, we determine the marginal value of real balances, $\lambda(z)=1+\xi(z)$, recursively. Suppose $z \in\left(z^{\star}-\bar{h}, z^{\star}\right)$. If the buyer can reach his targeted real balances by supplying less than $\bar{h}$, then the feasibility constraint on labor is slack, $\xi(z)=0$. As a result, $\lambda(z)=1$ and $W(z)$ is linear. From (18),

$$
\lambda(z)=\beta\left[\alpha \omega^{\prime}(z+\bar{h})+(1-\alpha) \lambda(z+\bar{h})\right], \text { for all } z \leq z^{\star}-\bar{h} .
$$

If a buyer enters the CM with $z \leq z^{\star}-\bar{h}$ real balances then he supplies his endowment of labor and enters the next period with $z+\bar{h}$. With probability $\alpha$ the buyer is matched and spends all his real balances. The

\footnotetext{
${ }^{11}$ Green and Zhou (1998), Zhou (1999), and Rocheteau (2000) also find geometric distributions of money holdings in search models with price posting and indivisible goods. However, the dynamics of individual real balances are different as individuals accumulate and deplete real balances one unit at a time.
} 
marginal value of a unit of money is then $\omega^{\prime}(z+\bar{h})$. With probability $1-\alpha$ the buyer is unmatched and enters the CM with $z+\bar{h}$, in which case the marginal value of money is $\lambda(z+\bar{h})$. The difference equation (32) can be solved in closed form to give:

$$
\lambda(z)=1+\alpha \sum_{j=1}^{+\infty} \beta^{j}(1-\alpha)^{j-1}\left[\omega^{\prime}(z+j \bar{h})-\omega^{\prime}\left(z^{\star}\right)\right]^{+},
$$

where $[x]^{+}=\max \{x, 0\}$. The marginal value of money is equal to one, the marginal disutility of work, plus the discounted sum of the differences between the marginal utility of DM consumption at a point in time and his marginal utility of consumption at the targeted real balances. It is easy to check that $\lambda(z)=W^{\prime}(z)$ is decreasing in $z$ (from the concavity of $u \circ v^{-1}(z)$ ) and continuous.

Given $\lambda(z)$ we can obtain the value function, $W(z)$, in closed form. At his targeted real balances the lifetime expected utility of a buyer is

$$
W\left(z^{\star}\right)=\beta\left\{\alpha\left[\omega\left(z^{\star}\right)+W(0)\right]+(1-\alpha) W\left(z^{\star}\right)\right\}
$$

The buyer does not need to readjust his real balances, and hence he incurs no cost in the CM. In the following DM he is matched with probability $\alpha$ in which case he depletes all his money balances. If he is unmatched he enters the subsequent $\mathrm{CM}$ with his targeted real balances. Multiplying both sides of (34) by $\beta^{-1}$ and using that $W\left(z^{\star}\right)-W(0)=\int_{0}^{z^{\star}} \lambda(x) d x, W\left(z^{\star}\right)$ can be rewritten as

$$
r W\left(z^{\star}\right)=\alpha\left[\omega\left(z^{\star}\right)-\int_{0}^{z^{\star}} \lambda(x) d x\right] .
$$

Given $W\left(z^{\star}\right)$ we obtain $W(z)$ as follows:

$$
W(z)=W\left(z^{\star}\right)-\int_{z}^{z^{\star}} \lambda(x) d x=\frac{\alpha}{r}\left[\omega\left(z^{\star}\right)-\int_{0}^{z^{\star}} \lambda(x) d x\right]-\int_{z}^{z^{\star}} \lambda(x) d x .
$$

We represent $W(z)$ in Figure 4.

The condition for full depletion of real balances is $\omega^{\prime}\left(z^{\star}\right) \geq \lambda(0)$. The marginal utility that the buyer gets from spending his last unit of real balances, $\omega^{\prime}\left(z^{\star}\right)$, must be greater than the marginal utility from holding onto this unit of money, $\lambda(0)$. From (33) the condition for full depletion is

$$
\omega^{\prime}\left(z^{\star}\right)-1=\frac{r}{\alpha} \geq \alpha \sum_{j=1}^{+\infty} \beta^{j}(1-\alpha)^{j-1}\left[\omega^{\prime}(j \bar{h})-\omega^{\prime}\left(z^{\star}\right)\right]^{+} .
$$

We represent the condition (37) by a grey area in Figure 5. The dotted lines represent the conditions in (25). The case studied in LRW, $N=1$, requires the endowment in labor, $\bar{h}$, to be large so that the buyer can readjust his money balances in a single period. If the endowment is such that $\omega^{\prime}(\bar{h})>1+r / \alpha$ then it will take more than one period for the buyer to reach his targeted real balances.

As indicated earlier, sellers who have linear preferences over CM consumption goods find it optimal to spend all their real balances in the $\mathrm{CM}$ since $\beta R<1$, i.e., the rate of return of money does not compensate sellers for their time preference. As a result, within each period sellers produce DM consumption goods in 


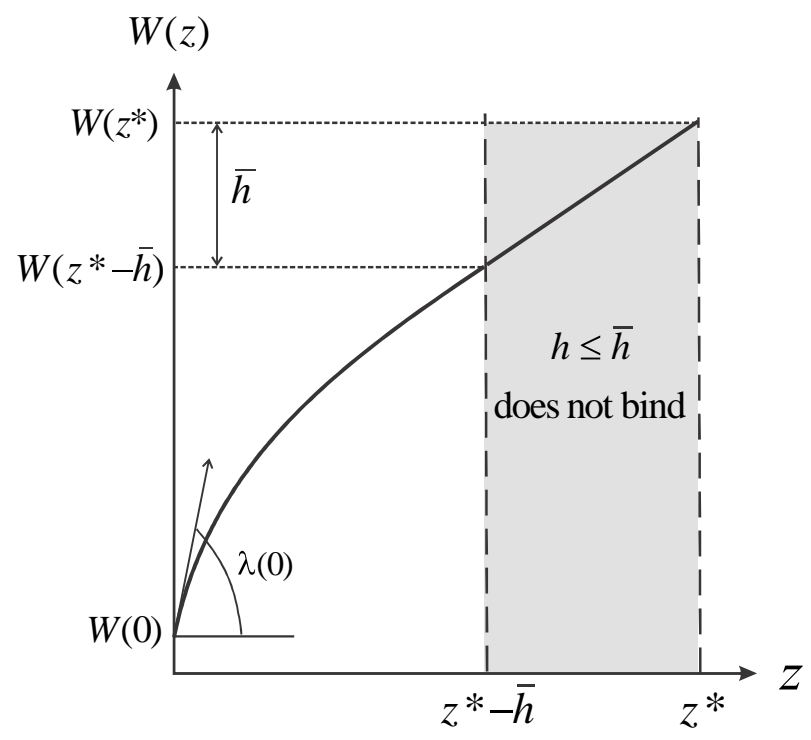

Figure 4: Value function at a steady-state monetary equilibrium

order to acquire real balances that they spend to purchase CM goods. Buyers are willing to acquire those real balances in order to purchase DM goods in following periods. We can now define a steady-state equilibrium as follows.

Definition 2 A steady-state, monetary equilibrium with full depletion of real balances is a list, $\left(N, z^{\star}, \phi,\left\{\mu_{n}\right\}_{n=1}^{N}\right)$, that solves (23), (25), (29)-(30), (31), and (37).

Provided that the condition for full depletion, (37), holds we construct a steady-state equilibrium as follows. From (23) we determine the targeted real balances, $z^{\star}$. We use (25) to compute the number of periods it takes to reach the target, $N$. Given $N$ and $z^{\star}$ the steady-state distribution of real balances is obtained from (29)-(30). Finally, the value of money is obtained from (31).

Proposition 3 (Existence of steady-state monetary equilibria with full depletion.) If (37) holds, then there exists a steady-state monetary equilibrium with full depletion. If $\omega^{\prime}(\bar{h}) \leq 1+r / \alpha$ then the equilibrium features $N=1$, i.e., there is a degenerate distribution of buyers' real balances. If $\omega^{\prime}(\bar{h})>1+r / \alpha$ then the equilibrium features $N \geq 2$, i.e., the distribution of buyers' real balances is non-degenerate.

We now characterize equilibria with full depletion when the length of a period of time, denoted $\Delta$, is small. Such limits are relevant because search-theoretic models of monetary exchange are typically viewed as models of high-frequency trade. The variables with a time dimension are $r, \alpha$, and $\bar{h}$. We index these variables by $\Delta$ and we denote $r_{\Delta}=r \Delta, \alpha_{\Delta}=\alpha \Delta$, and $\bar{h}_{\Delta}=\bar{h} \Delta$. From (24) the targeted real balances, $z^{\star}$, do not depend on $\Delta$. At sufficiently high frequency, $\Delta<\omega^{\prime-1}\left(1+\frac{r}{\alpha}\right) / \bar{h}$, any equilibrium features a nondegenerate distribution of real balances. Moreover, when the length of a time interval becomes very small, the geometric distribution of real balances converges to a truncated exponential distribution, $F(z) \rightarrow 1-e^{-\frac{\alpha z}{h}}$, 


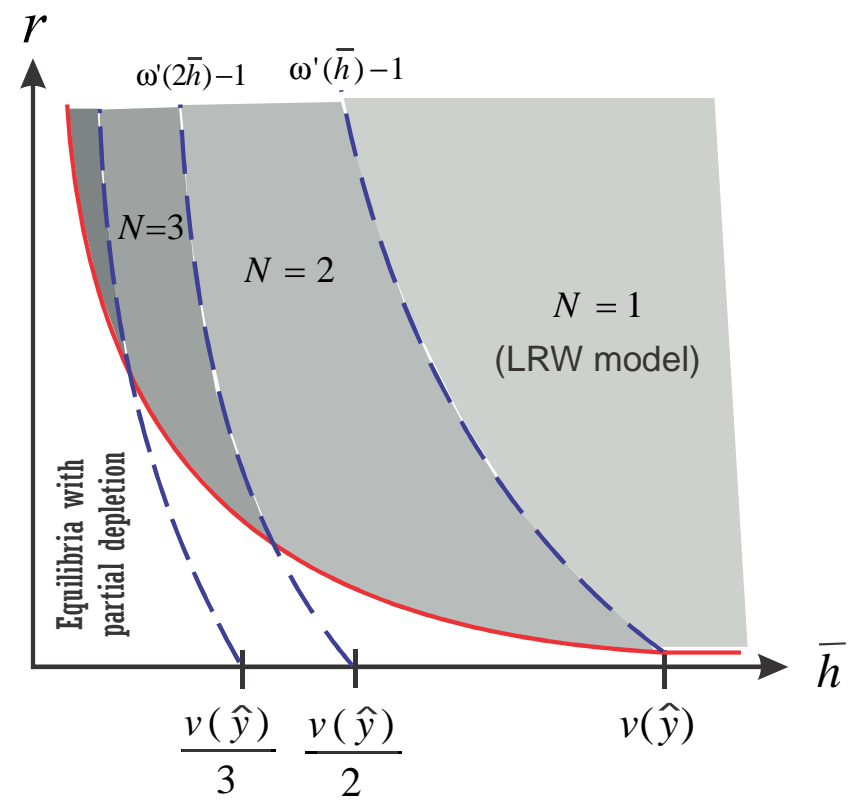

Figure 5: Existence of equilibria with full depletion of real balances

and aggregate real balances tend to $\bar{h}\left(1-e^{-\alpha T}\right) / \alpha$ where $T=z^{\star} / \bar{h} \cdot{ }^{12}$ These limits are analogous to the ones of the continuous-time economy of Rocheteau, Weill, and Wong (2015).

In order to illustrate the discussion above, we parameterize the model along the lines of Lucas (2000) and Lagos and Wright (2005). For now, take the unit of time to be a year. The rate of time preference is $r=0.03$. Adopt the following functional forms: $v(y)=y$ and $u(y)=y^{1-a} /(1-a)$. Assume that the total output in the $\mathrm{CM}$ is $\bar{h}$, i.e., buyers always produce the full amount and they consume whatever is in excess of their demand for real balances. This will make the calibration strategy identical to the one in Lagos-Wright. Total output is $\alpha z+\bar{h}$. Hence, the aggregate demand for money normalized by GDP is $L \equiv z /(\alpha z+\bar{h})$. In order to allow for inflation we assume a constant growth of the money supply by injecting $M_{t+1}-M_{t}=(\gamma-1) M_{t}$ at the beginning of each CM through lump-sum transfers to buyers only. (See Section 6.3 for details.) Assuming $N=1$ the buyer's choice of real balances generalizes (24) as follows: $\omega^{\prime}\left(z^{\star}\right)=1+i / \alpha$, where $i$ is defined as $1+i=(1+r) \gamma$. Under the functional forms above, the individual demand for real balances is $z=(1+i / \alpha)^{-1 / a}$. Hence, the aggregate demand for money is

$$
L=\frac{1}{\alpha+\bar{h}(1+i / \alpha)^{1 / a}} .
$$

Fixing $\alpha=0.5$, we find that the parameter values $\bar{h}=1.91$ and $a=0.15$ fit the US money demand. Given that $\bar{h}>1=v(\hat{y})$ we verify that $N=1$.

Now we change the unit of time from a year to a month by dividing $r, \alpha$ and $\bar{h}$ by $12 .{ }^{13}$ The stationary

\footnotetext{
${ }^{12}$ In order to determine the limit of the distribution we denote $t=n \Delta<T$ and $z_{t}=t \bar{h}<z^{*}$ and we take the limit as $\Delta$ goes to 0 and $n \Delta$ is kept constant and equal to $t$.

${ }^{13} \mathrm{By}$ doing this scaling we obtain parameter values that are very close to the ones of the monthly model of Lagos and Wright (2005, Table 3). They find $\alpha=0.033, a=0.2$, and $\bar{h}=0.17$ (using our own notations). Note that their method to pin down $\mathrm{CM}$ output, based on a logarithmic utility function, is slightly different from ours.
} 
equilibrium with constant money supply features $N=5$ and full depletion, i.e., it takes 5 months for a buyer to accumulate his targeted real balances assuming he does not receive any trading opportunity during these 5 months. The cumulative distribution of real balances is plotted in Figure 6 . If the unit of time is reduced to a week then the stationary equilibrium under a constant money supply features $N=17$, as shown in Figure 6 .

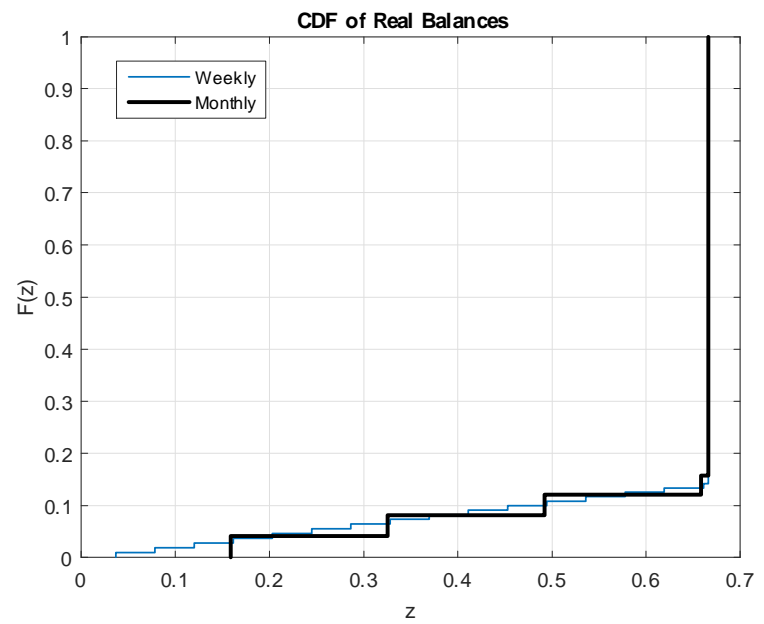

Figure 6: Distribution of real balances under the Lagos-Wright calibration: Monthly and weekly frequency

In order to illustrate how the choice of the unit of time matters quantitatively we redo the traditional exercise of Lucas (2000) that consists in computing the welfare cost of $10 \%$ inflation as the fraction of total consumption that agents would be willing to give up in order to have $0 \%$ inflation instead of $10 \%$. At the annual frequency this cost is about $1.6 \%$ of total consumption. If the unit of time is a month then the welfare cost of inflation drops to $1.32 \%$ of total consumption. At weekly frequency it is $1.30 \%$ of total consumption. The reason the cost of inflation is smaller when the unit of time is small is that the distribution is no longer degenerate, since there is a possibility that agents receive a trading opportunity before they have time to reach their targeted real balances. As a result, inflation through lump-sum transfers has now a positive welfare effect by providing risk sharing. This positive effect is worth about $0.3 \%$ of total consumption. So, by simply changing the unit of time from a year to a month, we introduce risk sharing considerations that lower the cost of inflation by about $20 \%$.

\section{Money in the short run}

We now study the short-run effects of a money injection. Following LRW, we assume that an agent's type as buyer or seller is observable so that the monetary authority can transfer $(\gamma-1) M$, with $\gamma>1$, in a lump-sum fashion to all buyers at the time they enter the CM of $t=0$. The change in the money supply is common knowledge among all agents.

As a benchmark, consider first equilibria with $N=1$, i.e., the distribution of money holdings is degenerate 
at the beginning of each period. From (11) and (17) the buyer's demand for real balances, $z_{t+1}^{\star}$, is determined by the following Euler equation:

$$
1=\beta R_{t+1}\left\{\alpha\left[\omega^{\prime}\left(z_{t+1}^{\star}\right)-1\right]+1\right\} \text { for all } t \geq 1 \text {. }
$$

Note that when the distribution of real balances is degenerate, $N=1$, individual real balances, $z_{t}^{\star}$, coincide with aggregate real balances, $\phi_{t} \gamma M$. Using $R_{1}=z_{1}^{\star} /\left(\phi_{0} \gamma M\right)$ and $R_{t+1}=z_{t+1}^{\star} / z_{t}^{\star}$ for all $t \geq 1$, a monetary equilibrium is a solution, $\left(\phi_{0},\left\{z_{t}^{\star}\right\}_{t=1}^{\infty}\right)$, to the following dynamic system with $\phi_{0}>0$ :

$$
\begin{aligned}
\phi_{0} \gamma M & =\beta z_{1}^{\star}\left\{\alpha\left[\omega^{\prime}\left(z_{1}^{\star}\right)-1\right]+1\right\} \\
z_{t}^{\star} & =\beta z_{t+1}^{\star}\left\{\alpha\left[\omega^{\prime}\left(z_{t+1}^{\star}\right)-1\right]+1\right\} \quad \text { for all } t \geq 1 .
\end{aligned}
$$

This system is solved recursively: $\left\{z_{t+1}^{\star}\right\}_{t=0}^{\infty}$ solves the difference equation (40) and $\phi_{0}$ is obtained from (39). ${ }^{14}$ The difference equation (40) has a unique positive fixed point, $z^{\star}$, solving $\omega^{\prime}\left(z^{\star}\right)=1+r / \alpha$. Given $z^{\star}$ we use (39) to obtain $\phi_{0}=z^{\star} / \gamma M$. So the economy reaches its steady state in the CM of $t=0$. Such a steady state exists if $\omega^{\prime}(\bar{h})<1+r / \alpha$.

The short-run neutrality of money can be explained as follows. At the beginning of the CM of $t=0$ there is a measure $1-\alpha$ of buyers holding $M$ and a measure $\alpha$ holding 0 . Following the transfer, the former hold $\gamma M$ while the latter hold $(\gamma-1) M$. If the rate of return of money is $R_{1}=\phi_{1} / \phi_{0}=1$, both types want to keep their real balances at $z^{\star}$, which is feasible since $\bar{h}>z^{\star}$. By market clearing, $\phi_{t} \gamma M=z^{\star}$, which implies $\phi_{1}=\phi_{0}=z^{\star} / \gamma M$. So buyers with $\gamma M$ hold onto their units of money (since the target in nominal terms is $\gamma M)$ while buyers with $(\gamma-1) M$ acquire $M$ additional units from sellers.

Proposition 4 (Neutral money injections) Suppose the economy is initially at a steady state with $N=1$ and consider a one-time money injection, $(\gamma-1) M$, via lump-sum transfers to buyers in the CM of $t=0$. There is an equilibrium such that the value of money adjusts instantly to its new steady-state value, $\phi_{0}=$ $z^{\star} / \gamma M$, and $R_{t}=1$ for all $t \geq 1$.

In the rest of this section we focus on equilibria with $N=2$, as it is the minimum heterogeneity needed for money injections to have real effects. The economy starts at a steady state at the beginning of $t=0$. Before entering the DM, there is a measure $\alpha$ of buyers holding $m_{\ell}=\bar{h} M /\left[\alpha \bar{h}+(1-\alpha) z^{\star}\right]$ units of money and a measure $1-\alpha$ holding $m_{h}=z^{\star} M /\left[\alpha \bar{h}+(1-\alpha) z^{\star}\right]$. At the beginning of the CM of $t=0$, after a round of DM trades, the distribution of money balances across buyers has three mass points: there is a measure $\alpha$ of buyers holding no money (the buyers who were matched in the previous DM), a measure $\alpha(1-\alpha)$ holding $m_{\ell}$ and a measure $(1-\alpha)^{2}$ holding $m_{h}$. This distribution is illustrated in Figure 7 .

We will distinguish small money injections that do not affect the number of mass points in the distribution of real balances from larger money injections such that the distribution $F_{t}$ is degenerate at $t=1$.

\footnotetext{
${ }^{14}$ Note that Lagos-Wright models, like other monetary models, have multiple dynamic equilibria. There are a continuum of inflationary equilibria such that the value of money decreases over time and converges asymptotically to 0 . These equilibria can be refined away by assigning a small commodity component to money. Depending on the curvature of $\omega$ there can also be multiple equilibria that converge to the unique steady state, periodic equilibria, and chaotic dynamics. For details, see Lagos and Wright (2003).
} 


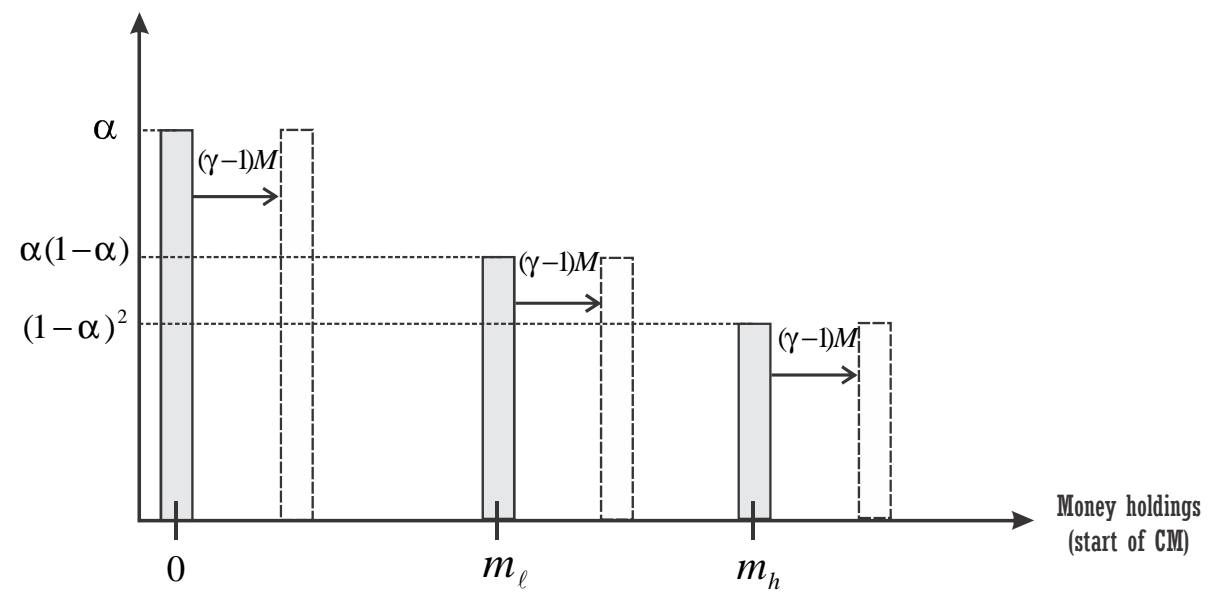

Figure 7: Distribution of money holdings at the start of the CM of $t=0$

\subsection{Small injection}

We consider first the case where $\gamma$ is close to 1 . By continuity with respect to the steady state we conjecture that at the beginning of every period $t \geq 1$ the distribution of real balances has two mass points, $z_{t}^{1}$ and $z_{t}^{\star}$. The quantity $z_{t}^{1}$ corresponds to the real balances of the measure $\alpha$ of buyers who depleted their money holdings in the previous DM. (The superscript "1" stands for the number of CMs since the buyer experienced his last DM match.) It solves:

$$
\begin{aligned}
& z_{1}^{1}=R_{1}\left[\bar{h}+(\gamma-1) \phi_{0} M\right] \\
& z_{t}^{1}=R_{t} \bar{h} \text { for all } t \geq 2 .
\end{aligned}
$$

According to (41) a buyer who enters the CM of $t=0$ with no money supplies $\bar{h}$ units of labor, which yields $R_{1} \bar{h}$ real balances at $t=1$, and he receives a lump-sum transfer of money of size $(\gamma-1) M$ valued at the price $\phi_{1}=R_{1} \phi_{0}$. According to (42) a buyer with depleted money holdings in the CM of $t-1 \geq 1$ saves his full labor endowment in order to enter the next DM of $t$ with $R_{t} \bar{h}$ real balances. The quantity $z_{t}^{\star}$ represents the real balances of the remaining $1-\alpha$ buyers who were unmatched in the DM of $t-1$. We guess and verify that those buyers were not constrained by their labor endowment and were able to reach their target, which from (38) can be reexpressed as:

$$
\omega^{\prime}\left(z_{t}^{\star}\right)=1+\frac{1+r-R_{t}}{\alpha R_{t}} \text { for all } t \geq 1 .
$$

Aggregate real balances are equal to the population-weighted average of $z_{t}^{1}$ and $z_{t}^{\star}$ :

$$
\phi_{t} \gamma M=\alpha z_{t}^{1}+(1-\alpha) z_{t}^{\star} \text { for all } t \geq 1 .
$$

From (44) written at two consecutive dates we obtain the following system to solve for $\phi_{0}$ and $\left\{R_{t}\right\}_{t=1}^{+\infty}$ :

$$
\begin{aligned}
\phi_{0} \gamma M & =\frac{\alpha z_{1}^{1}+(1-\alpha) z_{1}^{\star}}{R_{1}} \\
\alpha z_{t}^{1}+(1-\alpha) z_{t}^{\star} & =\frac{\alpha z_{t+1}^{1}+(1-\alpha) z_{t+1}^{\star}}{R_{t+1}} \text { for all } t \geq 1 .
\end{aligned}
$$


This system is the analog of (39)-(40) for equilibria that feature $N=2$. As before, it can also be solved recursively. Equation (46) for all $t \geq 2$ defines a first-order, non-linear difference equation in $R_{t}$. Given a solution $\left\{R_{t}\right\}_{t=2}^{+\infty}$ we can use (46) at $t=1$ and (45) to solve for $\left(\phi_{0}, R_{1}\right)$.

The difference equation (46) for $t \geq 2$ has a unique positive and constant solution, $R_{t}=1$. Hence, there exists an equilibrium that becomes stationary starting at $t=2$, with $z_{t}^{\star}=z^{\star}, z^{1}=\bar{h}$, and $R_{t}=1$ for all $t \geq 2$. Next, from (46) evaluated at $t=1$ and (45), the pair $\left(\phi_{0}, R_{1}\right)$ solves:

$$
\begin{aligned}
\phi_{0} \gamma M & =\frac{\alpha z_{1}^{1}+(1-\alpha) z_{1}^{\star}}{R_{1}} \\
\alpha z_{1}^{1}+(1-\alpha) z_{1}^{\star} & =\alpha \bar{h}+(1-\alpha) z^{\star} .
\end{aligned}
$$

Substituting $z_{1}^{1}$ by its expression given by (41) and solving (47) for aggregate real balances at $t=1$, we obtain:

$$
\phi_{1} \gamma M=\frac{\alpha R_{1} \bar{h}+(1-\alpha) z_{1}^{\star}}{1-\alpha\left(1-\frac{1}{\gamma}\right)} .
$$

Aggregate real balances at $t=1$ are a linear combination of the capitalized labor endowment, $R_{1} \bar{h}$, of buyers with depleted money balances and the targeted real balances, $z_{1}^{\star}$, of all other buyers. The term $[1-\alpha(1-1 / \gamma)]^{-1}$ is a multiplier arising from the fact that the transfer received by buyers is proportional to aggregate real balances.

From (48) and (49) we determine the gross real rate of return of fiat money from $t=0$ to $t=1$. It solves:

$$
\frac{\alpha R_{1} \bar{h}+(1-\alpha) z_{1}^{\star}}{1-\alpha\left(1-\frac{1}{\gamma}\right)}=\alpha \bar{h}+(1-\alpha) z^{\star} .
$$

The left side of $(50)$ is increasing in $R_{1}$ : it is equal to 0 when $R_{1}=0$ and greater than $\alpha \bar{h}+(1-\alpha) z^{\star}$ (because $1>\alpha\left(1-\gamma^{-1}\right)$ ) when $R_{1}=1$. Hence, there is a unique $R_{1}$ solution to (50) and it is such that $R_{1}<1$ and $\phi_{0}>\phi_{1}$. In words, aggregate real balances at the beginning of $t=1$ are increasing with the rate of return of money, $R_{1}$, because the $1-\alpha$ unconstrained buyers have incentives to accumulate higher real balances when the rate of return of money is high, and the $\alpha$ constrained buyers enjoy a higher rate of return on their (constrained) savings. Suppose the rate of return of money stays at its steady-state value, $R_{1}=1$. The real balances of unconstrained buyers are equal to their steady-state value, $z_{1}^{\star}=z^{\star}$, while the real balances of constrained buyers, $z_{1}^{1}=\bar{h}+(\gamma-1) \phi_{0} M$, are larger than their steady-state value, $\bar{h}$, which is inconsistent with an equilibrium where the economy returns to its steady state in the CM of $t=1$. Hence, the rate of return of money falls below one in order to clear the market by reducing the targeted real balances of the unconstrained buyers.

Figure 8 illustrates the determination of the equilibrium value for $R_{1}$, denoted $R_{1}^{e}$, where the left side of (50) is represented by the upward-sloping red curve. As $\gamma$ increases this curve shifts upward and, as a result, $R_{1}^{e}$ decreases. Moreover, $\lim _{\gamma \downarrow 1} R_{1}(\gamma)=1$. So despite prices being flexible and all agents having access to the centralized market, the value of money does not adjust instantly to its new steady-state value and money is not neutral in the short run. ${ }^{15}$

\footnotetext{
${ }^{15}$ Results are qualitatively similar if the money supply increases though transfers to all agents in the economy.
} 


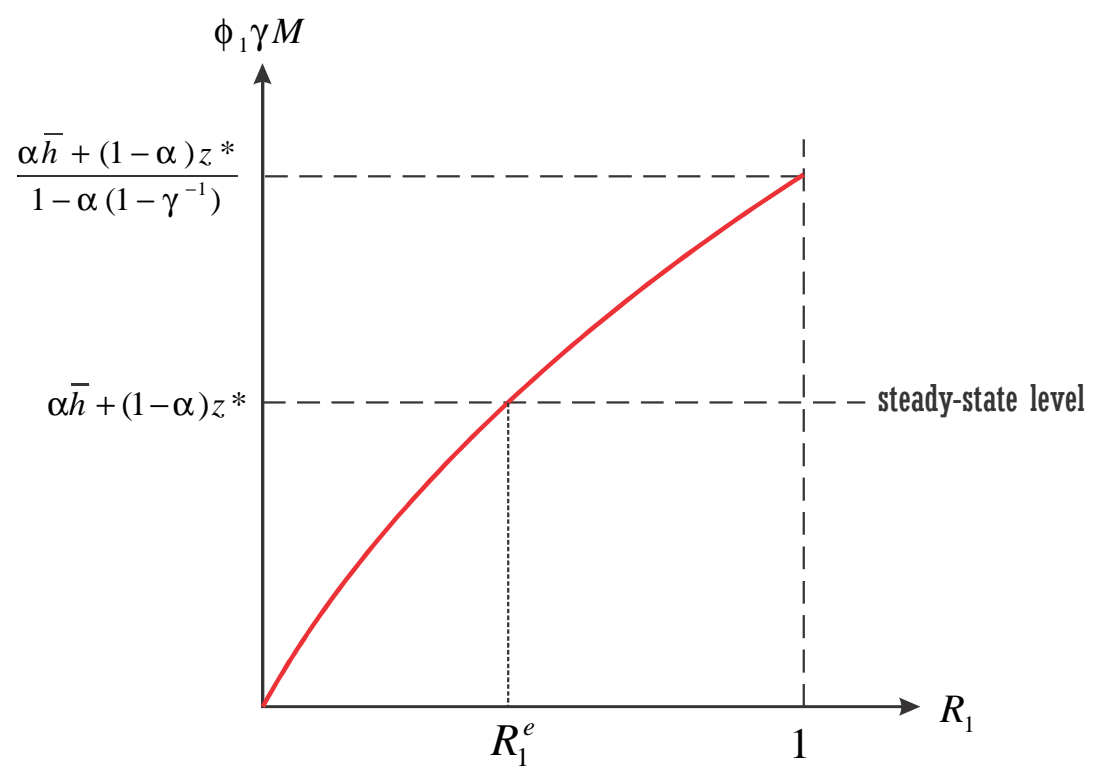

Figure 8: Determination of $R_{1}$

Given $R_{1}$ the value of money at the time of the money injection is $\phi_{0}=\phi_{1} / R_{1}$. Using the expression for $\phi_{1} \gamma M$ given by (48):

$$
\phi_{0}=\frac{\alpha \bar{h}+(1-\alpha) z^{\star}}{R_{1} \gamma M} .
$$

This ends our characterization of the solution to the dynamic system (39)-(40). The Appendix lists the conditions for an equilibrium featuring two mass points at the beginning of each period. In the rest of the section we describe additional properties of the equilibrium in terms of price and output effects.

Short-run prices. Let $\phi_{-1}=\left[\alpha \bar{h}+(1-\alpha) z^{\star}\right] / M=\gamma \phi_{1}$ denote the value of money at the initial steady state. We determine the condition under which a small increase in $\gamma$ above 1 raises the value of money at $t=0$, $\phi_{0}$, above its initial steady-state value, $\gamma \phi_{1}$, i.e., there is deflation in the short run. Since $\phi_{0} / \phi_{-1}=1 /\left(R_{1} \gamma\right)$, it is equivalent to check the condition under which $R_{1}<1 / \gamma$. Differentiating $R_{1}$ defined in (50) with respect to $\gamma$ we show that

$$
\left.\frac{d R_{1} / R_{1}}{d \gamma / \gamma}\right|_{\gamma=1}<-1 \Leftrightarrow \frac{-z^{\star} \omega^{\prime \prime}\left(z^{\star}\right)}{\omega^{\prime}\left(z^{\star}\right)}>\frac{z^{\star}}{\left(z^{\star}-\bar{h}\right) \beta \alpha(\alpha+r)} .
$$

It can easily be checked from (43) that the inverse "long-run" elasticity of money demand, $\left(d R_{t} / R_{t}\right) /\left(d z_{t}^{\star} / z_{t}^{\star}\right)$, is proportional to the term $-z^{\star} \omega^{\prime \prime}\left(z^{\star}\right) / \omega^{\prime}\left(z^{\star}\right)$. So if the long-run money demand is sufficiently inelastic, the clearing of the money market in the CM of $t=0$ requires a large fall in $R_{1}$. Given that $\phi_{1}$ is pinned down by its steady-state value, the large fall in $R_{1}$ required to clear the market is achieved by an increase of $\phi_{0}$ above its initial steady-state value.

Output and labor-supply effects. The output levels in the DM of $t=1$ are $y_{\ell, 1}=v^{-1}\left(z_{1}^{1}\right)>v^{-1}(\bar{h})$ and $y_{h, 1}=v^{-1}\left(z_{1}^{\star}\right)<v^{-1}\left(z^{\star}\right)$. Hence, the money injection reduces the dispersion of output and consumption 
levels across matches. Aggregate output is

$$
Y_{1}=\alpha y_{\ell, 1}+(1-\alpha) y_{h, 1} \geq Y^{s s}=\alpha v^{-1}(\bar{h})+(1-\alpha) v^{-1}\left(z^{\star}\right)
$$

with a strict inequality if $v$ is strictly convex. The $1-\alpha$ buyers who hold their targeted real balances make smaller payments relative to the steady state, because $R_{1}<1$, while the $\alpha$ buyers who depleted their money holdings in the previous DM make larger payments because they benefited from lump-sum transfers. Total real balances spent in the DM are the same as in the steady state, but output is higher due to the seller's convex cost, i.e., the drop in consumption for the richest buyers is smaller than the increase for the poorest ones. Hence, DM aggregate output increases relative to its steady-state value, $Y^{s s}$. We summarize these results in Figure 9 by plotting the trajectories for aggregate real balances, $\phi_{t} \gamma M$, and DM output levels.

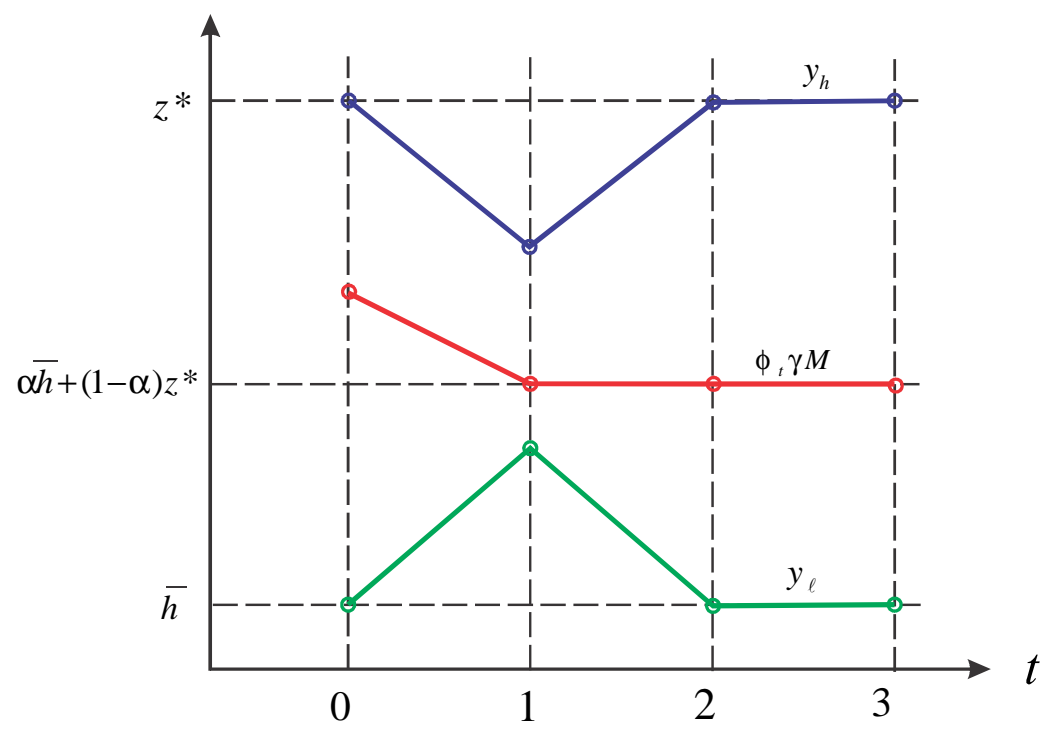

Figure 9: Effects of a small money injection

Next, we turn to CM aggregate output, denoted $H_{t} \equiv \int h_{t}(i) d i$, where $h_{t}(i)$ is the choice of $h$ at time $t$ by buyer $i$. Summing the buyers' budget constraints in the CM of $t=0,(5)$, we find:

$$
H_{0}=\alpha \bar{h}+\alpha(1-\alpha) h_{0}\left(m_{\ell}\right)+(1-\alpha)^{2} h_{0}\left(m_{h}\right)
$$

with

$$
\begin{aligned}
h_{0}\left(m_{\ell}\right) & =\left\{\frac{z_{1}^{\star}}{R_{1}}-\phi_{0}\left[m_{\ell}+(\gamma-1) M\right]\right\}^{+} \\
h_{0}\left(m_{h}\right) & =\left\{\frac{z_{1}^{\star}}{R_{1}}-\phi_{0}\left[m_{h}+(\gamma-1) M\right]\right\}^{+} .
\end{aligned}
$$

The first term on the right side of (53) corresponds to the labor supply of the buyers with depleted money holdings: those buyers supply their labor endowment. The second term corresponds to the labor supply of buyers with $m_{\ell}$ units of money, $h_{0}\left(m_{\ell}\right)$, and the third term is the labor supply of buyers with $m_{h}$ units of 
money, $h_{0}\left(m_{h}\right)$. From (54) and (55) buyers holding $m_{\ell}$ and $m_{h}$ accumulate their targeted real balances, $z_{1}^{\star} / R_{1}$, and their wealth is composed of their initial real balances and the real transfer of money. (We assume that buyers who supply labor in the $\mathrm{CM}, h>0$, do not consume, $c=0$.) By definition of the money holdings at the initial steady state, $\phi_{0} m_{\ell}=\bar{h} /\left(R_{1} \gamma\right)$ and $\phi_{0} m_{h}=z^{\star} /\left(R_{1} \gamma\right)$. Moreover, aggregate real balances are $\phi_{0} M=\left[\alpha \bar{h}+(1-\alpha) z^{\star}\right] /\left(\gamma R_{1}\right)$. Substituting these expressions into (54)-(55) and using (50) to express $z_{1}^{\star}$ as a function of $\gamma$ and $R_{1}$, i.e.,

$$
\gamma z_{1}^{*}=\frac{[(1-\alpha) \gamma+\alpha]\left[\alpha \bar{h}+(1-\alpha) z^{\star}\right]-\alpha \gamma R_{1} \bar{h}}{1-\alpha}
$$

we obtain the following individual labor supplies:

$$
\begin{aligned}
h_{0}\left(m_{\ell}\right) & =\frac{\left\{\alpha \bar{h}\left(1-\gamma R_{1}\right)+(1-\alpha)\left(z^{\star}-\bar{h}\right)\right\}^{+}}{(1-\alpha) \gamma R_{1}} \\
h_{0}\left(m_{h}\right) & =\frac{\alpha \bar{h}\left\{1-\gamma R_{1}\right\}^{+}}{(1-\alpha) \gamma R_{1}} .
\end{aligned}
$$

From (57) and (58) individual labor supplies are decreasing in $\gamma R_{1}=\gamma \phi_{1} / \phi_{0}=\phi_{-1} / \phi_{0}$. Moreover, when $\gamma R_{1}=1$ labor supplies are at their steady-state levels. Hence, when $\gamma R_{1}<1$ - the value of money at $t=0$ is larger than the one at the initial steady state - aggregate CM output is larger than its steady-state value. Conversely, when $\gamma R_{1}>1$ it is lower than its steady-state value. So high CM output is associated with deflation while low $\mathrm{CM}$ output is associated with inflation.

In summary, the $\alpha$ buyers with depleted money holdings have an inelastic labor supply, $\bar{h}$. So all the action in terms of output changes comes from the $1-\alpha$ buyers entering the CM with positive money holdings, $m_{\ell}$ and $m_{h}$. There are three effects. First, there is a standard wealth effect under quasi-linear preferences according to which any change in the buyer's wealth leads to a one-to-one change in the buyer's labor supply in the opposite direction. Buyers' wealth changes because they receive a lump-sum transfer of real balances and because the value of money decreases by a factor $\phi_{-1} / \phi_{0}=\gamma R_{1}$ relative to its initial steady-state value. Second, buyers reduce their target, $z_{1}^{\star}$, because of the lower rate of return of money, $R_{1}$, which tends to reduce the labor supply. Third, the real value of the target in $t=0, z_{1}^{\star} / R_{1}$, is higher than its value in $t=1$ due to inflation, which tends to raise the labor supply. When $\gamma R_{1}=1$ these three effects cancel out. If $\gamma R_{1}<1$, which happens when the money demand from unconstrained buyers is inelastic, then the third effect dominates and buyers holding $m_{\ell}$ and $m_{h}$ units of money supply more labor in the short run in order to maintain their targeted real balances, thereby generating a fall in the price level.

We summarize the results of this section in the following proposition.

Proposition 5 (Small money injection.) Suppose the economy is initially at a steady state with $N=2$. A small, one-time money injection, $(\gamma-1) M$, in the $C M$ of $t=0$ has the following consequences:

1. It raises aggregate real balances, $\phi_{0} \gamma M$, above their steady-state value, and reduces the gross rate of return of money, $R_{1}$, below one. 
2. If (52) holds and $\gamma$ is close to 1 , then $\phi_{0}>\gamma \phi_{1}$, i.e., there is deflation in the short run, and CM output increases, $H_{0}>H_{1}$.

3. It generates a mean-preserving reduction in the distribution of real balances in the DM of $t=1$, an increase in aggregate DM output if $v^{\prime \prime}>0$, and an increase in society's welfare.

4. The economy returns to its steady state in the $C M$ of $t=1$.

So far we have considered increases in the money supply. The empirical evidence regarding monetary shocks is often stated in terms of shocks that are contractionary. In the context of our model this means $\gamma<1$, i.e., the monetary authority withdraws $(1-\gamma) M$ through lump-sum taxation. We assume that the government can enforce the payment of taxes and $1-\gamma$ is not too large so that buyers with depleted money balances can afford the tax. The effects of a contraction of the money supply are symmetric to the ones described in Proposition 5.

Corollary 1 ("Price puzzle") Consider a one-time contraction of the money supply, $\gamma<1$. If (52) holds, then $\phi_{0}<\gamma \phi_{1}$, i.e., there is inflation in the short run, and CM output decreases, $H_{0}<H_{1}$.

This finding is consistent with the "price puzzle" from Eichenbaum (1992) according to which a contractionary shock to monetary policy raises the price level in the short run. Moreover, Christiano, Eichenbaum, and Evans (1999, Section 4.4.3) document that a contractionary shock to $M 1$ leads output to fall during two quarters and then to rise. In our model output falls in the CM and following DM and then rises back to its steady-state value.

Proposition 5 is obtained under the assumption that money transfers were received by buyers only. It is straightforward to show that parts 1, 3, and 4 of the proposition go through if both buyers and sellers receive the lump-sum transfer. However, whether Part 2 of Proposition 5 holds or not depends on the measure of sellers, $\sigma$. To see this, suppose now that both buyers and sellers receive a transfer equal to $(\gamma-1) M /(1+\sigma)$. We show in the Appendix that the one-time money injection reduces the rate of return of money, $R_{1}<1$, and generates short-run deflation, $\phi_{0}>\gamma \phi_{1}$, if and only if:

$$
\frac{-z^{\star} \omega^{\prime \prime}\left(z^{\star}\right)}{\omega^{\prime}\left(z^{\star}\right)}>\frac{(1+\sigma) z^{\star}}{\left[z^{\star}-\left(1+\frac{\sigma}{1-\alpha}\right) \bar{h}\right] \beta \alpha(r+\alpha)} .
$$

Given that the right side of (59) is increasing in $\sigma$, it follows that a short-run deflation is less likely to occur when the transfer goes to both buyers and sellers. In particular, if $\sigma=1$, there is an equal measure of buyers and sellers, then the inequality never holds. So a one-time money injection can generate a deflation in the short run provided that $z^{\star}$ is sufficiently inelastic with respect to $R$ and the transfer is not diluted among a too-large measure of sellers.

Next, we disentangle the effects of money injections according to the recipients of the transfers. Suppose that the transfer is only received by sellers or buyers holding $m_{\ell}$ or $m_{h}$. Those agents are not constrained by their endowments when choosing real balances in the CM. We show in the Appendix that $R_{1}=1$, i.e., 
money is neutral. As long as money is not transferred to the buyers for whom $h \leq \bar{h}$ binds, then the money injection has no real effect. Suppose in contrast that the money injection happens through transfers to buyers with depleted money balances. Such transfers require that the monetary authority can observe the money holdings of buyers. Then, $R_{1}<1$ and there is short-run deflation if and only if:

$$
\frac{-\omega^{\prime \prime}\left(z^{\star}\right) z^{\star}}{\omega^{\prime}\left(z^{\star}\right)}>\frac{1}{\beta(r+\alpha)}
$$

This condition is weaker than (59) or (52). So the "price puzzle" is more easily explained for money injections that target the poorest agents and for such interventions non-neutralities are the largest.

\subsection{Large injections}

We now consider the case of a large money injection with the maintained assumption that lump-sum transfers go to buyers only. We focus on equilibria where transfers are large enough so that even the buyers who enter the CM of $t=0$ with depleted money holdings can reach their target $z_{1}^{\star}$ solution to (43), i.e., the distribution of real balances is degenerate. Such an equilibrium is a $\phi_{0}$ and $\left\{R_{t}\right\}_{t=1}^{+\infty}$ solution to the dynamic system, (39)-(40), where $z_{1}^{1}=z_{1}^{\star}$. By the same reasoning as before, $R_{1}$ is determined by (39) and (40) at $t=1$ under the condition that the economy has reached its steady state in the $\mathrm{CM}$ of $t=1$ :

$$
z_{1}^{\star}=\alpha \bar{h}+(1-\alpha) z^{\star}
$$

The right side of (61), $z_{1}^{\star}$, tends to 0 as $R_{1}$ approaches 0 and is equal to $z^{\star}$ when $R_{1}=1$. Hence, (61) determines a unique $R_{1}<1$, which is independent of $\gamma$. Therefore, an increase in the size of the money injection affects current and future prices in the same proportion so as to keep their ratio, $\phi_{1} / \phi_{0}$, constant. As before, the money injection generates a mean-preserving decrease in the spread of the distribution of real balances across buyers. Aggregate output in the DM of $t=1$ is

$$
Y_{1}=v^{-1}\left[\alpha \bar{h}+(1-\alpha) z^{\star}\right] \geq Y^{s s}=\alpha v^{-1}(\bar{h})+(1-\alpha) v^{-1}\left(z^{\star}\right) .
$$

The ouput is independent of the size of the money injection, but is larger than the steady-state value provided that $v^{\prime \prime}>0$.

We need to check that the buyers who enter the CM of $t=0$ with no money balances are not constrained by their endowment of labor. This will be the case if $R_{1} \bar{h}+\left(1-\frac{1}{\gamma}\right) \phi_{1} \gamma M>z_{1}^{\star}$, i.e.,

$$
\gamma R_{1}>\frac{\alpha \bar{h}+(1-\alpha) z^{\star}}{\bar{h}} .
$$

So an equilibrium with a degenerate distribution of real balances at $t=1$ exists provided that the size of the transfer is sufficiently large. Moreover, from (62) the rate of return of money is $R_{1}>\gamma^{-1}$. So for large money injections it is always the case that $\phi_{0}<\left[\alpha \bar{h}+(1-\alpha) z^{\star}\right] / M$; prices increase relative to their initial steady-state value. As a result, from (58), buyers holding $m_{h}$ do not supply any labor. Buyers holding no money supply

$$
h_{0}^{+}(0)=\frac{z_{1}^{\star}}{R_{1}}-(\gamma-1) \phi_{0} M=\frac{\alpha \bar{h}\left(1-\gamma R_{1}\right)+(1-\alpha) z^{\star}}{(1-\alpha) \gamma R_{1}} .
$$


From (57) and (63) both $h_{0}^{+}(0)$ and $h_{0}^{+}\left(m_{\ell}\right)$ decrease with $\gamma R_{1}$. Using that $\gamma R_{1}>1$ it follows that aggregate output in the CM of $t=0$ is lower than its steady-state value.

Proposition 6 (Large money injection.) Suppose the economy is initially at a steady state with $N=2$. A large one-time money injection, $(\gamma-1) M$, in the CM of $t=0$ such that (62) holds has the following consequences:

1. It raises aggregate real balances, $\phi_{0} \gamma M$, above their steady-state value, and reduces the gross rate of return of money, $R_{1}$, below one. Moreover, $\phi_{0}<\gamma \phi_{1}$ and $H_{0}<H_{1}$.

2. The distribution of real balances is degenerate in the DM of $t=1$ and DM aggregate output is higher than its steady-state value if $v^{\prime \prime}>0$.

3. The economy returns to its steady state in the $C M$ of $t=1$.

\subsection{Long-lasting effects of a one-time money injection}

So far we have restricted our attention to equilibria with $N=2$ because such equilibria generate simple, one-period transitions to a steady state. We now consider steady states with $N \geq 3$ and assume a small injection of money so that the distribution of real balances preserves $N$ mass points with probabilities given by (29)-(30). We will focus on equilibria with full depletion.

An equilibrium can now be described as a sequence, $\left\{\phi_{t},\left(z_{t}^{j}\right), z_{t+1}^{\star}\right\}_{t=0}^{+\infty}$, solution to the following system of difference equations:

$$
\begin{aligned}
\phi_{t} \gamma M & =\sum_{j=1}^{N-1} \mu_{j} z_{t}^{j}+\mu_{N} z_{t}^{\star} \text { for all } t \geq 1 \\
\phi_{0} \gamma M & =\sum_{j=1}^{N-1} \mu_{j} z_{0}^{j}+\mu_{N} \frac{z_{1}^{\star}}{R_{1}} \\
z_{t}^{j} & =R_{t}\left(z_{t-1}^{j-1}+\bar{h}\right) \text { for all } t \geq 1 \text { and } j \in\{1, \ldots, N-1\} \\
z_{t}^{0} & =0 \text { for all } t \geq 1 \\
z_{0}^{j} & =\phi_{0}\left[m^{j-1}+(\gamma-1) M\right]+\bar{h} \text { for all } j \in\{1, \ldots, N-1\} \\
\omega^{\prime}\left(z_{t}^{\star}\right) & =1+\frac{1-\beta R_{t}}{\alpha \beta R_{t}} .
\end{aligned}
$$

Equation (64) defines aggregate real balances as the sum of individual real balances at the beginning of each period $t \geq 1$. The right side of (64) indexes buyers by the last time they had a DM encounter and depleted their money balances. There is a measure $\mu_{j}$ of buyers who entered the CM of $t-j$ with depleted money balances, with $j \leq N-1$. From (66) those buyers entered period $t$ with real balances inherited from period $t-1, z_{t-1}^{j-1}$, plus their labor endowment, $\bar{h}$, capitalized at the rate of return of money, $R_{t}$. There is a measure $\mu_{N}$ of buyers who have reached their target as defined in (69). Equation (65) defines aggregate real balances in the CM of $t=0$ where individual real balances, $z_{0}^{j}$, are obtained from the initial steady state according to (68), and $m^{j}$ indicates the steady-state nominal money balances of a buyer who had a DM match $j$ periods 


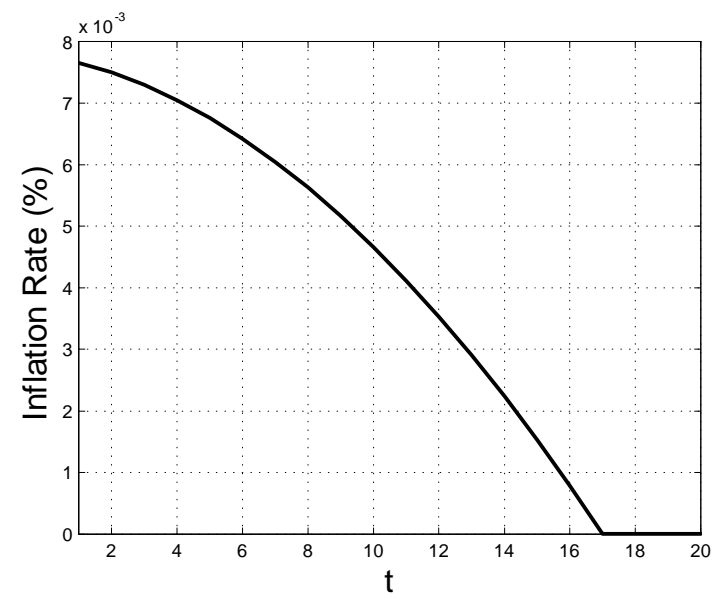

Figure 10: Weekly inflation rate following a one-time $5 \%$ increase in the money supply

ago when the aggregate money supply was $M$. (The exact expression is provided in the Appendix.) The transition to a steady state is long lived because the real balances of a buyer whose last match was in $t-j$, with $j<N-1$, depends on the sequence of past rates of return, $R_{t-j+1}$ to $R_{t}$.

In Figure 10 we provide a numerical example for the transitional dynamics of the inflation rate, $\pi_{t}=$ $\phi_{t-1} / \phi_{t}-1$, following a one-time money injection. We take the same functional forms as in Section 4 . If we take the period of time to be a year, so that $N=1$, then the value of money adjusts instantly to its steadystate value, i.e., $\phi_{1}=\phi_{0} / 1.05$ or, equivalently, $\pi_{1}=5 \%$. For all following periods, $t>1, \pi_{t}=0$. In Figure 10 the unit of time is a week so that the laissez-faire steady-state equilibrium features a non-degenerate distribution with $N=17$ mass points. The transitional dynamics for a $5 \%$ increase in the money supply differs from the one at the yearly frequency in that inflation is persistent and the inflation rate returns to 0 only asymptotically. Numerically convergence to the steady state takes about $N=17$ periods, which is analogous to our analysis of equilibria with $N=2$. The weekly inflation rate peaks initially at about $0.008 \%$, which is about $0.4 \%$ inflation annually. It falls in a monotonic fashion over the following 17 weeks. To sum up, at a weekly frequency the effect of a monetary shock on inflation is spread out across a large number of periods and the pick of inflation is mild relative to an annual model.

\section{Money and unemployment risk}

So far we have considered an environment where the only idiosyncratic risk comes from the random matching process in the decentralized goods market. We now extend the model to add idiosyncratic employment shocks formalized as shocks on labor endowments, $\bar{h} \in\left\{\bar{h}^{U}, \bar{h}^{E}\right\}$, with $0<\bar{h}^{U}<\bar{h}^{E}$. ${ }^{16}$ We can think of $\bar{h}^{E}$ as the income of the buyer who is employed in the CM and $\bar{h}^{U}$ the income of a buyer who is unemployed in

\footnotetext{
${ }^{16}$ The description of the employment shocks is analogous to the one in Algan, Challe, and Ragot (2011). We differ from this model in that we consider an environment with search and bargaining where the idiosyncratic risk comes from both matching opportunities in a decentralized market and employment shocks in a centralized market.
} 
the CM. The transition from $E$ (employment state) to $U$ (unemployment state) occurs at the beginning of a period with probability $s$ (think of $s$ as the separation rate) while the transition from $U$ to $E$ occurs with probability $f$ (think of $f$ as the job finding rate). ${ }^{17}$ We define the unemployment rate as the fraction of buyers in state $U$. This extension allows us to study how money injections affect allocations and prices depending on the equilibrium unemployment rate.

\subsection{Equilibria with full depletion}

We focus on equilibria with full depletion of real balances. We define $\mu_{n, m}^{\chi}$ as the measure of buyers who went through $n$ periods of employment (state $E$ in the $\mathrm{CM}$ ) and $m$ periods of unemployment (state $U$ in the $\mathrm{CM})$ since their last DM match, and whose current employment state upon entering the DM is $\chi \in\{E, U\}$. These buyers hold $n \bar{h}^{E}+m \bar{h}^{U}$ real balances. Let $\mathbb{H}=\left\{(n, m) \in \mathbb{N}_{0}^{2} \backslash(0,0): n \bar{h}^{E}+m \bar{h}^{U}<z^{\star}\right\}$ be the set of employment histories, $(n, m)$, for which buyers have not reached their target. The distribution of buyers across states is defined recursively as follows:

$$
\begin{aligned}
& \mu_{n, m}^{E}=(1-s) \mu_{n-1, m}^{E}+f \mu_{n, m-1}^{U} \\
& \mu_{n, m}^{U}=s \mu_{n-1, m}^{E}+(1-f) \mu_{n, m-1}^{U},
\end{aligned}
$$

for all $(n, m) \in \mathbb{H}$ and $n, m>0$. According to (70) a buyer is in state $(n, m, E)$ if: (i) he was in state $(n-1, m, E)$ in the past period, in which case he enjoyed an endowment of $\bar{h}^{E}$ in his last CM, and he remained employed with probability $1-s$; (ii) he was in state $(n, m-1, U)$ in the past period, in which case he enjoyed an endowment of $\bar{h}^{U}$ in his last CM, and he became employed with probability $f$. Equation (71) has a similar interpretation. If $n=0$ or $m=0$ we have:

$$
\begin{array}{ll}
\mu_{1,0}^{E}=(1-s) \alpha \mu^{E}, & \mu_{1,0}^{U}=s \alpha \mu^{E} \\
\mu_{0,1}^{U}=(1-f) \alpha \mu^{U}, & \mu_{0,1}^{E}=f \alpha \mu^{U}
\end{array}
$$

where $\mu^{\chi}$ is measure of agents in labor state $\chi \in\{E, U\}$. According to (72) there is a measure $\mu^{E}$ of buyers entering the DM in state $E$. A fraction $\alpha$ of those buyers deplete their money holdings. In the following CM they accumulate $\bar{h}^{E}$ and stay in state $E$ with probability $1-s$ or they transition to state $U$ with probability $s$. Equation (73) has a similar interpretation. At the steady state $\left(1-\mu^{U}\right) s=\mu^{U} f$ so that the measure of unemployed buyers is $\mu^{U}=s /(s+f)$. Hence,

$$
\mu^{E}=\frac{f}{s+f}, \quad \mu^{U}=\frac{s}{s+f} .
$$

Finally, the measures of buyers at the targeted real balances are given by:

$$
\begin{aligned}
& \mu_{z^{\star}}^{E}=\frac{f}{s+f}-\sum_{(n, m) \in \mathbb{H}} \mu_{n, m}^{E} \\
& \mu_{z^{\star}}^{U}=\frac{s}{s+f}-\sum_{(n, m) \in \mathbb{H}} \mu_{n, m}^{U} .
\end{aligned}
$$

\footnotetext{
${ }^{17}$ The description of employment/unemployment is similar to the one in Ljungqvist and Sargent (1998) where wages are drawn from an exogenous distribution.
} 
Equations (70)-(76) define the distribution of buyers across states, $\left\{\mu_{n, m}^{\chi}, \mu_{z^{\star}}^{\chi}\right\}$, recursively. Aggregate real balances are:

$$
\phi M=\sum_{(n, m) \in \mathbb{H}}\left(\mu_{n, m}^{E}+\mu_{n, m}^{U}\right)\left(n \bar{h}^{E}+m \bar{h}^{U}\right)+\left(\mu_{z^{\star}}^{E}+\mu_{z^{\star}}^{U}\right) z^{\star} .
$$

The value of money increases with the income in the two employment states, $\bar{h}^{E}$ and $\bar{h}^{U}$; it increases with the job finding rate, $f$; and it decreases with the separation rate, $s$. So the value of money is negatively correlated with the unemployment rate.

The marginal value of real balances for a buyer in state $\chi \in\{U, E\}$ solves

$$
\lambda^{\chi}(z)=\beta\left\{\alpha \omega^{\prime}\left(z+\bar{h}^{\chi}\right)+(1-\alpha)\left[\left(1-\delta^{\chi}\right) \lambda^{\chi}\left(z+\bar{h}^{\chi}\right)+\delta^{\chi} \lambda^{\chi^{\prime}}\left(z+\bar{h}^{\chi}\right)\right]\right\}
$$

for all $z \leq z^{\star}-\bar{h}^{U}, \chi \in\{U, E\}, \chi^{\prime} \in\{U, E\} \backslash\{\chi\}$ and where the transition probabilities are $\delta^{E}=s$ and $\delta^{U}=f$. For all $z \in\left[z^{\star}-\bar{h}^{\chi}, z^{\star}\right], \lambda^{\chi}(z)=1$. Using that $\lambda^{U}(z) \geq \lambda^{E}(z)$ for all $z$, the condition for full depletion of real balances is

$$
\lambda^{U}(0) \leq \omega^{\prime}\left(z^{\star}\right)=1+\frac{r}{\alpha} .
$$

As before, this condition holds provided that agents are sufficiently impatient.

\subsection{Simple equilibria with constrained unemployed}

In order to simplify the analysis further, suppose now that employed buyers can reach the targeted real balances in a single period while unemployed workers need two periods to accumulate $z^{\star}$, i.e.,

$$
\bar{h}^{U}<\omega^{\prime-1}\left(1+\frac{r}{\alpha}\right) \leq \min \left\{2 \bar{h}^{U}, \bar{h}^{E}\right\} .
$$

The marginal value of real balances for an employed buyer is $\lambda^{E}(z)=1$ for all $z$ on the support of the distribution. So employed buyers are similar to the agents in the Lagos-Wright model: their choice of real balances is unaffected by their labor endowment. From (78) the marginal value of real balances for an unemployed buyer solves

$$
\lambda^{U}(z)=\beta\left\{\alpha \omega^{\prime}\left(z^{\prime}\right)+(1-\alpha)\left[f+(1-f) \lambda^{U}\left(z^{\prime}\right)\right]\right\}
$$

where $z^{\prime}=\min \left\{z+\bar{h}^{U}, z^{\star}\right\}$. The condition for full depletion of real balances, (79), can be reexpressed as

$$
\frac{r}{\alpha}>\alpha \beta\left[\omega^{\prime}\left(\bar{h}^{U}\right)-\omega^{\prime}\left(z^{\star}\right)\right] .
$$

So the endowment of the unemployed, $\bar{h}^{U}$, cannot be too low-in particular, it cannot be zero-since otherwise the buyer would not want to deplete his money holdings in full when matched in the DM. From (77) the steady-state aggregate real balances simplify to

$$
\phi M=\alpha \mu^{U} \bar{h}^{U}+\left(1-\alpha \mu^{U}\right) z^{\star} .
$$

The value of money increases with the income of unemployed workers, $\bar{h}_{U}$, and decreases with the unemployment rate, $\mu^{U} \cdot{ }^{18}$

\footnotetext{
${ }^{18}$ The chanel through which unemployment affects the value of money is different from the one in Berentsen, Menzio, and Wright (2011) where $\bar{h}^{U}$ is large enough to allow unemployed workers to accumulate $z^{\star}$. In that model it is assumed that $\alpha$ is an increasing function of aggregate employment, $1-\mu^{U}$, so that an increase in $\mu^{U}$ reduces $\alpha$ and hence $z^{\star}$.
} 
Consider a small money injection through a lump-sum transfer to all buyers. Unemployed buyers who had depleted their real balances in $t=0$ enter the following period with $z_{1}^{0}=R_{1} \bar{h}^{U}+(\gamma-1) \phi_{1} M$. The real balances of the unemployed buyer who depleted his money holdings in the last DM corresponds to his income when unemployed times the rate of return of currency, $R_{1} \bar{h}^{U}$, plus the real transfer of money, $(\gamma-1) \phi_{1} M$. This transfer is analogous to some unemployment insurance financed with a proportional tax on money holdings. Following the same reasoning as above, the rate of return of money solves

$$
\frac{\alpha \mu^{U} R_{1} \bar{h}^{U}+\left(1-\alpha \mu^{U}\right) z_{1}^{\star}}{1-\alpha \mu^{U}\left(1-\frac{1}{\gamma}\right)}=\alpha \mu^{U} \bar{h}^{U}+\left(1-\alpha \mu^{U}\right) z^{\star} .
$$

Accordingly, the effect of a money injection on the rate of return of money depends on the unemployment rate as represented by $\mu^{U}$. If $\mu^{U}$ is small, then money is almost neutral whereas if $\mu^{U}$ is large a money injection has real effects.

\subsection{Beneficial inflation and unemployment risk}

So far we have described a one-time, unanticipated change in the quantity of money. ${ }^{19}$ We now turn to the case where the government implements a constant growth of the money supply by injecting $M_{t+1}-M_{t}=$ $(\gamma-1) M_{t}$ at the beginning of each CM, where $\gamma$ is close to 1 , through lump-sum transfers to buyers only. We focus on steady-state equilibria where aggregate real balances are constant. The gross rate of return of money is $R=\gamma^{-1}$. Generalizing (18) the marginal value of real balances solves

$$
\lambda^{\chi}(z)=\frac{\beta}{\gamma}\left\{\alpha \omega^{\prime}\left(z^{\prime}\right)+(1-\alpha) \mathbb{E} \lambda^{\chi^{\prime}}\left(z^{\prime}\right)\right\}, \quad \chi \in\{U, E\},
$$

where the expectation is with respect to the future employment state, $\chi^{\prime} \in\{U, E\}$, conditional on the current employment state, $\chi$. At the target $z=z^{\prime}=z_{\gamma}^{\star}$ with $\lambda^{\chi}\left(z^{\star}\right)=1$ for all $\chi \in\{U, E\}$. Hence, from (84) $z_{\gamma}^{\star}$ solves

$$
\omega^{\prime}\left(z_{\gamma}^{\star}\right)=1+\frac{\gamma-\beta}{\beta \alpha} .
$$

Suppose first that $\bar{h}^{E}>\bar{h}^{U}>z^{\star}$, which will be the case if $\omega^{\prime}\left(\bar{h}^{U}\right)<1+(\gamma-\beta) / \beta \alpha$. All buyers, irrespective of their labor state, can accumulate their targeted real balances in a single CM ,as is the case in Berentsen, Menzio, and Wright (2011). As $\gamma$ rises above one, aggregate real balances, $Z \equiv \phi_{t} M_{t}=z_{\gamma}^{\star}$, CM and DM output, and welfare, $\mathcal{W}_{\gamma}=\alpha\left[\omega\left(z_{\gamma}^{\star}\right)-z_{\gamma}^{\star}\right]$, decrease. Indeed, there is no trade-off for monetary policy between risk sharing and self insurance since there is no ex-post heterogeneity in terms of real balances. Hence, monetary policy should only promote self insurance by raising the rate of return of currency. ${ }^{20}$

Proposition 7 (Constant money growth with degenerate distributions.) Consider a laissez-faire equilibrium with $\gamma=1$ and $\bar{h}^{E}>\bar{h}^{U}>z^{\star}$. An increase of $\gamma$ reduces aggregate real balances, output, and social welfare.

\footnotetext{
${ }^{19}$ More precisely, we have assumed that agents do not assign a positive probability to a change in the money supply ahead of time. However, when the change in the money supply happens it is common knowledge.

${ }^{20}$ In Berentsen, Menzio, and Wright (2011) inflation reduces firm entry and hence can raise welfare in the presence of congestion externality.
} 
For the rest of the section we study equilibria where buyers in state $E$ have enough endowment to reach their target, $\bar{h}^{E}>z^{\star}$, while buyers in state $U$ need two rounds of CM to reach $z^{\star}, \bar{h}^{U}<z^{\star}<2 \bar{h}^{U}$. At the beginning of each period the distribution of real balances has two mass points. There is a measure $\alpha \mu^{U}$ of buyers holding $z_{\ell} \equiv \gamma^{-1} \bar{h}^{U}+(\gamma-1) \phi_{t} M_{t-1}$. Those unemployed buyers depleted their money holdings in the previous DM, supplied their full labor endowment in the CM, and held onto the money transfer provided by the government. There is a measure $1-\alpha \mu^{U}$ of buyers holding their targeted real balances, $z_{\gamma}^{\star}$. Aggregate real balances are

$$
Z \equiv \phi_{t} M_{t}=\alpha \mu^{U}\left[\frac{\bar{h}^{U}}{\gamma}+\left(1-\gamma^{-1}\right) \phi_{t} M_{t}\right]+\left(1-\alpha \mu^{U}\right) z_{\gamma}^{\star}
$$

Solving for $Z$ we obtain:

$$
Z=\frac{\alpha \mu^{U} \gamma^{-1} \bar{h}^{U}+\left(1-\alpha \mu^{U}\right) z_{\gamma}^{\star}}{1-\alpha \mu^{U}\left(1-\gamma^{-1}\right)}
$$

Aggregate real balances (and CM output) are a weighted average of the buyer's labor endowment when unemployed and his targeted real balances, where the weights vary with the money growth rate and the unemployment rate. The term $\left[1-\alpha \mu^{U}\left(1-\gamma^{-1}\right)\right]^{-1}$ is a multiplier according to which the transfer, proportional to aggregate real balances, is saved by the $\alpha \mu^{U}$ buyers who are unemployed and have depleted money holdings. As $\gamma$ increases the weight on $\bar{h}^{U}$ decreases, which tends to raise real balances, but the targeted real balances decrease, which tends to reduce aggregate real balances. As the unemployment rate increases, aggregate real balances decrease. From (87) the real balances of the poorest unemployed buyers, $z_{\ell}$, are

$$
z_{\ell}=\frac{\gamma^{-1} \bar{h}^{U}+\left(1-\gamma^{-1}\right)\left(1-\alpha \mu^{U}\right) z_{\gamma}^{\star}}{\alpha \mu^{U} \gamma^{-1}+1-\alpha \mu^{U}}
$$

If the unemployment rate is higher, then aggregate real balances are lower and the lump-sum transfer to unemployed buyers with depleted real balances is lower, which reduces their real balances. Differentiating $z_{\ell}$ we obtain

$$
\left.\frac{d z_{\ell}}{d \gamma}\right|_{\gamma=1}=\left(1-\alpha \mu^{U}\right)\left(z^{\star}-\bar{h}^{U}\right)>0 .
$$

For low inflation rates $z_{\ell}$ increases with $\gamma$ while $z_{\gamma}^{\star}$ decreases with $\gamma$. This effect corresponds to the redistributional role of inflation. The overall effect on aggregate real balances is given by:

$$
\left.\frac{\partial Z}{\partial \gamma}\right|_{\gamma=1}=\left(1-\alpha \mu^{U}\right)\left[\alpha \mu^{U}\left(z^{\star}-\bar{h}^{U}\right)+\frac{1}{\beta \alpha \omega^{\prime \prime}\left(z^{\star}\right)}\right] .
$$

A small inflation raises aggregate real balances if the following inequality holds:

$$
\frac{-\omega^{\prime \prime}\left(z^{\star}\right) z^{\star}}{\omega^{\prime}\left(z^{\star}\right)}>\frac{z^{\star}}{(r+\alpha) \beta \alpha \mu^{U}\left(z^{\star}-\bar{h}^{U}\right)} .
$$

If $\omega^{\prime}$ is very elastic then a change in $\gamma$ does not affect buyers' target much but it raises the real balances of the poorest buyers by the amount of the lump-sum transfer. In this case a small increase in $\gamma$ generates an increase in the mean of the distribution of real balances and a decrease in its dispersion. Hence, welfare increases. Note also that condition (89) is more likely to hold when the unemployment rate is high since the measure of buyers who are unable to reach the target increases with $\mu^{U}$. 
We define society's welfare at a steady state with money growth rate $\gamma$ by

$$
\mathcal{W}_{\gamma}=\alpha^{2} \mu^{U}\left[\omega\left(z_{\ell}\right)-z_{\ell}\right]+\left(1-\alpha \mu^{U}\right) \alpha\left[\omega\left(z_{\gamma}^{\star}\right)-z_{\gamma}^{\star}\right] .
$$

The first term on the right side of (90) corresponds to matches between an unemployed buyer holding $z_{\ell}$ and a seller. There is a measure $\alpha \mu^{U}$ of such buyers and each of them has a probability $\alpha$ of being matched, so the total number of matches is $\alpha^{2} \mu^{U}$. The second term of the welfare function corresponds to matches between buyers holding their targeted real balances - there is a measure $1-\alpha \mu^{U}$ of such buyers - and sellers. We differentiate $\mathcal{W}_{\gamma}$ in the neighborhood of a constant money supply to obtain:

$$
\left.\frac{d \mathcal{W}_{\gamma}}{d \gamma}\right|_{\gamma=1}=\left(1-\alpha \mu^{U}\right)\left\{\alpha^{2} \mu^{U}\left[\omega^{\prime}\left(\bar{h}^{U}\right)-1\right]\left(z^{\star}-\bar{h}^{U}\right)+\frac{r}{\beta \alpha \omega^{\prime \prime}\left(z^{\star}\right)}\right\} .
$$

Hence, inflation is welfare improving if

$$
\frac{-\omega^{\prime \prime}\left(z^{\star}\right) z^{\star}}{\omega^{\prime}\left(z^{\star}\right)}>\frac{r}{(r+\alpha) \beta \alpha^{2} \mu^{U}\left[\omega^{\prime}\left(\bar{h}^{U}\right)-1\right]}\left(\frac{z^{\star}}{z^{\star}-\bar{h}^{U}}\right) .
$$

A positive inflation rate is more likely to be optimal when the unemployment rate, $\mu^{U}$, is high or when the labor income of the unemployed, $\bar{h}^{U}$, is low. Indeed, the risk sharing benefits of inflation are larger when the income of the unemployed, $\bar{h}^{U}$, is far from their desired level of insurance, $z^{\star}$, and when the measure of buyers with low labor endowments, $\mu^{U}$, is large.

Proposition 8 (Optimal inflation and unemployment.) Consider a laissez-faire equilibrium with $\gamma=$ $1, z^{\star}<\bar{h}^{E}$, and $\bar{h}^{U}<z^{\star}<2 \bar{h}^{U}$. Moreover, assume that the equilibrium features full depletion of money holdings, i.e., (81) holds. Anticipated inflation through lump-sum transfers to buyers raises aggregate real balances if (89) holds and it raises social welfare if (91) holds.

\section{Conclusion}

We constructed a tractable model of monetary exchange with alternating market structures - search-andbargaining and price taking - featuring a non-degenerate distribution of real balances that can be used to study the short-run and long-run effects of monetary policy. Our model admits the Lagos-Wright equilibria with degenerate distribution of money holdings (conditional on types) as a special case. At high time frequency, equilibria featuring nondegenerate distributions and ex-post heterogeneity are generic and respond differently to policy than equilibria with degenerate distributions. For instance, we showed that a one-time injection of money in a centralized market with flexible prices leads to higher aggregate real balances in the short run and changes in output levels (the sign of which depends on fundamentals). Hence, money is not neutral in the short run despite flexible prices and perfect information. The effects on the rate of return of money and prices are non-monotone with the size of the money injection. If the long-run money demand is sufficiently inelastic, an expansionary monetary shock generates deflation in the short run. We provided examples where money non-neutralities are long lived. Finally, we studied a version of the model with both random-matching risk and employment risk. We showed that a constant money growth rate can lead to higher output and welfare if the unemployment rate is large and agents are sufficiently risk averse. 


\section{References}

[1] Algan, Yann, Edouard Challe, and Lionel Ragot (2011). "Incomplete markets and the output-inflation trade-off," Economic Theory 46, 55-84.

[2] Berentsen, Aleksander, Gabriele Camera, and Christopher Waller (2005). "The distribution of money balances and the nonneutrality of money," International Economic Review, 46, 465-487.

[3] Berentsen, Aleksander., Guido Menzio, \& Randall Wright (2011). "Inflation and unemployment in the long run," The American Economic Review, 371-398.

[4] Camera, Gabriele, and Dean Corbae (1999). "Money and price dispersion," International Economic Review 40, 985-1008.

[5] Chiu, Jonathan, and Miguel Molico (2010). "Liquidity, redistribution, and the welfare cost of inflation," Journal of Monetary Economics 57, 428-438.

[6] Chiu, Jonathan, and Miguel Molico (2011). "Uncertainty, inflation, and welfare," Journal of Money, Credit, and Banking, 43, 487-512.

[7] Chiu, Jonathan, and Miguel Molico (2014). "Short-run dynamics in a search-theoretic model of monetary exchange," Working Paper.

[8] Christiano, Lawrence, Martin Eichenbaum, Charles Evans (1999). "What have we learned and to what end?" in Handbook of Macroeconomics, ed. Michael Woodford and John D. Taylor.

[9] Coibion, Olivier, Yuriy Gorodnichenko, Lorenz Kueng and John Silvia (2012). "Innocent bystanders? Monetary policy and inequality in the U.S.," Working Paper.

[10] Diamond, Peter and Joel Yellin (1985). "The distribution of inventory holdings in a pure exchange barter search economy," Econometrica 53, 409-432.

[11] Doepke, Matthias, and Martin Schneider (2006). "Inflation and the redistribution of nominal wealth," Journal of Political Economy 114, 1069-1097.

[12] Eichenbaum, Martin (1992) "Comment on interpreting the macroeconomic time series facts: The effects of monetary policy," European Economic Review 36, 1001-1011.

[13] Faig, Miquel, and Zhe Li (2009). "The welfare costs of expected and unexpected inflation." Journal of Monetary Economics 56, 1004-1013.

[14] Green, Edward and Ruilin Zhou (1998). "A rudimentary random-matching model with divisible money and prices," Journal of Economic Theory 81, 252-271.

[15] Jin, Gu, and Tao Zhu (2014). "Non neutrality of money in dispersion: Hume revisited," Working Paper. 
[16] Lagos, Ricardo and Guillaume Rocheteau (2005). "Inflation, output and welfare," International Economic Review 46, 495-522.

[17] Lagos, Ricardo and Randall Wright (2003). "Dynamics, cycles, and sunspot equilibria in 'genuinely dynamic, fundamentally disaggregative' models of money," Journal of Economic Theory 109, 156-171.

[18] Lagos, Ricardo and Randall Wright (2005). "A unified framework for monetary theory and policy analysis," Journal of Political Economy 113, 463-484.

[19] Ljungqvist, Lars, and Thomas Sargent (1998). "The European unemployment dilemma," Journal of Political Economy 106, 514-550.

[20] Lucas Jr, Robert E (2000). "Inflation and welfare," Econometrica 68, 247-274.

[21] Menzio, Guido, Shouyong Shi, and Hongfei Sun (2013), "Monetary theory with non-degenerate distributions", Journal of Economic Theory 148, 2266-2312.

[22] Milgrom, Paul, and Segal, Ilya (2002), "Envelope Theorems for arbitrary choice sets", Econometrica 70, 583-601.

[23] Molico, Miguel (2006). "The distribution of money and prices in search equilibrium," International Economic Review 47, 701-722.

[24] Rincoón-Zapatero, Juan Pablo and Santos, Manuel (2009). "Differentiability of the Value Function without Interiority Assumptions," Journal of Economic Theory, 144, 1948-1964.

[25] Rockafellar, Ralph Tyrell (1970). "Convex Analysis," Princeton University Press.

[26] Rocheteau, Guillaume, Pierre-Olivier Weill, and Tsz-Nga Wong (2015). "A tractable model of monetary exchange with ex-post heterogeneity," NBER Working Paper 21179.

[27] Rocheteau, Guillaume, and Randall Wright (2005). "Money in search equilibrium, in competitive equilibrium, and in competitive search equilibrium," Econometrica 73, 175-202.

[28] Scheinkman, Jose, and Laurence Weiss (1986). "Borrowing constraints and aggregate economic activity", Econometrica 54, 23-45.

[29] Shi, Shouyong (1995). "Money and prices: A model of search and bargaining," Journal of Economic Theory $67,467-496$.

[30] Stokey, Nancy, Robert Lucas, and Edward Prescott (1989). Recursive Methods in Economic Dynamics. Cambridge, Harvard University Press.

[31] Sun, Hongfei (2012). "Monetary and fiscal policies in a heterogeneous-agent economy," Working Paper. 
[32] Trejos, Alberto and Randall Wright (1995). "Search, bargaining, money, and prices," Journal of Political Economy 103, 118-141.

[33] Wallace, Neil (1997). "Short-run and long-run effects of changes in money in a random-matching model," Journal of Political Economy 105, 1293-1307.

[34] Williamson, Stephen (2006). "Search, limited participation, and monetary policy," International Economic Review 47, 107-128.

[35] Zhou, Ruilin (1999). "Individual and aggregate real balances in a random-matching model," International Economic Review 40, 1009-1038.

[36] Zhu, Tao (2005). "Existence of a monetary steady state in a matching model: Divisible money", Journal of Economic Theory 123, 135-160.

[37] Zhu, Tao (2008). "An overlapping-generations model with search," Journal of Economic Theory 142, 318-331. 


\section{Appendix A1: Proofs of Propositions 1 and 2}

This appendix provides a detailed analysis of the buyer's dynamic programming problem, leading to the results summarized in Propositions 1 and 2.

\section{A.1.1. Elementary Properties of Value Functions}

Consider the pair of Bellman equations, for all $t \in\{0,1,2, \ldots\}$ :

$$
\begin{aligned}
V_{t}(z) & =\sup \left\{\alpha\left[\omega(p)+W_{t}(z-p)\right]+(1-\alpha) W_{t}(z)\right\} \\
W_{t}(z) & =\sup _{z^{\prime}, h, c}\left\{\min \{c, \bar{c}\}+\bar{h}-h+\beta V_{t+1}\left(z^{\prime}\right)\right\}
\end{aligned}
$$

First, we substitute the Bellman equation for $V_{t}(z)$ into the Bellman equation for $W_{t}(z)$. Formally:

Lemma 1 The functions $W_{t}(z)$ and $V_{t}(z)$ solve the Bellman equations (92)-(93) if and only if

$$
W_{t}(z)=\max \left\{\min \{c, \bar{c}\}+\bar{h}-h+\beta \alpha\left[\omega(p)+W_{t+1}\left(z^{\prime}-p\right)\right]+\beta(1-\alpha) W_{t+1}\left(z^{\prime}\right)\right\}
$$

with respect to $c \geq 0,0 \leq h \leq \bar{h}, z^{\prime}=R_{t+1}(z-c+h)$, and $0 \leq p \leq z^{\prime}$.

Next, we apply standard contraction-mapping arguments to this Bellman equation. We obtain:

Lemma 2 The Bellman equations (92)-(93) have unique bounded solutions, $V_{t}(z)$ and $W_{t}(z)$. The functions $V_{t}(z)$ and $W_{t}(z)$ are continuous, concave, strictly increasing, and they satisfy

$$
\|W\| \leq \frac{\bar{c}+\bar{h}+\beta \alpha\|\omega\|}{1-\beta} \text { and }\|V\| \leq \frac{\bar{c}+\bar{h}+\alpha\|\omega\|}{1-\beta} .
$$

Proof. Consider the space $C\left(\mathbb{N} \times \mathbb{R}_{+}\right)$of bounded and continuous functions from $\mathbb{N} \times \mathbb{R}_{+}$to $\mathbb{R}$, equipped with the sup norm. By Theorem 3.1 in Stokey, Lucas, and Edward Prescott (1989, henceforth SLP), this is a complete metric space. Now, for any $f \in C\left(\mathbb{N} \times \mathbb{R}_{+}\right)$, consider the Bellman operator:

$$
T[f]_{t}(z)=\max \left\{\min \{c, \bar{c}\}+\bar{h}-h+\beta \alpha\left[\omega(p)+f_{t+1}\left(z^{\prime}-p\right)\right]+\beta(1-\alpha) f_{t+1}\left(z^{\prime}\right)\right\}
$$

with respect to $c \geq 0,0 \leq h \leq \bar{h}, z^{\prime}=R_{t+1}(z-c+h)$, and $0 \leq p \leq z^{\prime}$. It is straightforward to verify that $T$ satisfies the Blackwell sufficient condition for a contraction (Theorem 3.3 in SLP). Moreover, the constraint set is non-empty, compact valued, and continuous. Hence by the Theorem of the Maximum (Theorem 3.6 in SLP), we obtain that $T[f]$ is continuous. It is clearly bounded since all the functions on the right-hand side of the Bellman equation are bounded. Note as well that if $f$ is concave, then $T[f]$ is also concave since the objective is concave and the constraint correspondence has a convex graph. An application of the Contraction Mapping Theorem (Theorem 3.2 in SLP) implies that the fixed point problem $f=T[f]$ has a unique bounded solution, $W_{t}(z)$, and that this solution is continuous and concave.

Also, consider any two $z_{1}$ and some feasible $c_{1}, h_{1}, z_{1}^{\prime}, p_{1}$. Then, for $z_{2} \geq z_{1}$, the following choice is feasible: $c_{2}=c_{1}+z_{2}-z_{1}, h_{2}=h_{1}, z_{2}^{\prime}=z_{1}^{\prime}$ and $p_{2}=p_{1}$. That is, a buyer starting with $z_{2}$ can always consume $z_{2}-z_{1}$ and otherwise behave as if he started with $z_{1}$. Since this yield (weakly) higher utility 
this implies that $T[W]_{t}(z)=W_{t}(z)$ is increasing. Hence, the bounded solution of the Bellman equation is increasing. One also sees that it must be, in fact, strictly increasing. Indeed, a buyer starting at $z_{2}>z_{1}$ can wait to use $z_{2}-z_{1}$ in order to pay for more consumption in the DM, in which he receives a match with strictly positive probability. Since $\omega(p)$ is strictly increasing, this implies that $T[W]_{t}(z)=W_{t}(z)$ is strictly increasing.

Given a fixed point $W_{t}(z)$ of the Bellman operator $T$, we can define $V_{t}(z)$ as in equation (92). By identical arguments as above, one sees that $V_{t}(z)$ is bounded, continuous, concave, and strictly increasing.

Finally, we can derive upper bounds for $W_{t}(z)$ and $V_{t}(z)$. From the Bellman equation we have:

$$
\|W\| \leq \bar{c}+\bar{h}+\beta \alpha[\|\omega\|+\|W\|]+\beta(1-\alpha)\|W\| \Rightarrow\|W\| \leq \frac{\bar{c}+\bar{h}+\beta \alpha\|\omega\|}{1-\beta} .
$$

We obtain the bound on $\|V\|$ following identical arguments but for $V_{t}(z)$.

For the rest of this section, we slightly simplify the Bellman equation by reducing the number of optimizing variables. To do so, we first note that, since $W_{t}(z)$ is strictly increasing, it is strictly suboptimal for a buyer to choose $c>\bar{c}$ : the buyer can instead reduce consumption, with no loss of utility, and choose higher savings $z^{\prime}$. Hence, in the objective of the Bellman equation, we can replace $\min \{c, \bar{c}\}+\bar{h}-h$ by $\bar{h}+c-h$ : hence, the objective only depend on the difference $c-h$. The law of motion of $z^{\prime}$ implies in turn that $c-h=z-z^{\prime} / R_{t+1}$. Substituting this expression in the objective, and keeping in mind that $0 \leq h \leq \bar{h}$ and $0 \leq c \leq \bar{c}$, we can rewrite the Bellman equation as:

$$
W_{t}(z)=\max \left\{z-\frac{z^{\prime}}{R_{t+1}}+\bar{h}+\beta \alpha\left[\omega(p)+W_{t+1}\left(z^{\prime}-p\right)\right]+\beta(1-\alpha) W_{t+1}\left(z^{\prime}\right)\right\} .
$$

with respect to $z^{\prime}$ and $p$ and subject to $R_{t+1}(z-\bar{c}) \leq z^{\prime} \leq R_{t+1}(z+\bar{h})$ and $0 \leq p \leq z^{\prime}$.

It will be sometimes convenient to rewrite this equation differently, using the indirect utility for real balance in the DM as:

$$
\Omega_{t}(z)=\max _{0 \leq p \leq z}\left\{\omega(p)+W_{t}(z-p)\right\} .
$$

With this new notation, the Bellman equation becomes:

$$
W_{t}(z)=\max \left\{z-\frac{z^{\prime}}{R_{t+1}}+\bar{h}+\beta \alpha \Omega_{t+1}\left(z^{\prime}\right)+\beta(1-\alpha) W_{t+1}\left(z^{\prime}\right)\right\} .
$$

with respect to $z^{\prime} \geq 0$ and subject to $R_{t+1}(z-\bar{c}) \leq z^{\prime} \leq R_{t+1}(z+\bar{h})$.

\section{A.1.2. Elementary properties of decision rules}

We first consider the problem of a buyer in the DM, (95).

Lemma 3 The buyer's problem in the DM has a unique solution, $p_{t}(z)$. This solution is continuous, increasing, satisfies $\lim _{z \rightarrow 0} p_{t}(z)=0$ and $\lim _{z \rightarrow \infty} p_{t}(z)=\infty$. The value of the buyer in the DM, $\Omega_{t}(z)$, is continuous, strictly increasing, concave, and satisfies $\Omega_{t}^{\prime}\left(z^{+}\right) \geq \omega^{\prime}\left[p_{t}(z)\right]$.

Proof. Note first that this problem is strictly concave since we have assumed that $\omega(p)$ is strictly concave. Hence, it has a unique solution, which we denote by $p_{t}(z)$. Together with the Theorem of the Maximum (SLP 
Theorem 3.6), uniqueness implies that $p_{t}(z)$ is continuous. To show that $p_{t}(z)$ is increasing, consider any two $z_{1}<z_{2}$. If $p_{t}\left(z_{2}\right) \geq z_{1}$, then by feasibility it immediately follows that $p_{t}\left(z_{1}\right) \leq z_{1} \leq p_{t}\left(z_{2}\right)$. Otherwise, if $p_{t}\left(z_{2}\right)<z_{1}$, then a first-order condition for $z_{2}$ is that

$$
\omega^{\prime}\left[p_{t}\left(z_{2}\right)\right] \leq W_{t}^{\prime}\left[z_{2}-p_{t}\left(z_{2}\right)^{+}\right]
$$

where we recall that $W_{t+1}(z)$ is concave and so it has left- and right-derivatives for all $z>0$. By concavity we also have that $W_{t+1}^{\prime}\left(z^{+}\right)$is decreasing, which implies from the above equation that:

$$
\omega^{\prime}\left[p_{t}\left(z_{2}\right)\right] \leq W_{t+1}^{\prime}\left[z_{1}-p_{t}\left(z_{2}\right)^{+}\right]
$$

so $p_{t}\left(z_{1}\right) \leq p_{t}\left(z_{2}\right)$.

Because of the feasibility constraint, $0 \leq p \leq z$, it immediately follows that $\lim _{z \rightarrow 0} p(z)=0$. Suppose that $p(z)$ is bounded away from infinity. Then the first-order condition $\omega^{\prime}(p) \leq W_{t}\left[(z-p)^{-}\right]$cannot hold for $z$ large enough because $W_{t}(z)$ must satisfy Inada condition at infinity. Indeed, since $W_{t}(z)$ is bounded, increasing, and concave, we have $0 \leq W^{\prime}\left(z^{-}\right) z \leq W_{t}(z)-W_{t}(0) \leq\|W\|$, so that $\lim _{z \rightarrow \infty} W^{\prime}\left(z^{-}\right)=0$.

The value $\Omega_{t}(z)$ is continuous by the Theorem of the Maximum. It is strictly increasing because $W_{t}(z)$ is strictly increasing: a buyer can always keep any additional unit of cash for the next CM, which increases his utility strictly. To establish the lower bound on the right derivative, we note that, $p_{t}(z)$ is feasible for any $z^{\prime} \geq z$. This implies that, for all $z^{\prime} \geq z$ :

$$
\Omega_{t}\left(z^{\prime}\right) \geq \omega\left[p_{t}(z)+z^{\prime}-z\right]+W_{t+1}\left[z^{\prime}-p_{t}(z)\right]
$$

with equality if $z=z^{\prime}$. The result follows by subtracting the equality for $z=z^{\prime}$ to the above inequality, dividing by $z^{\prime}-z$, and letting $z^{\prime} \rightarrow z^{+}$.

To solve for an optimal money holdings decision, we proceed as follows. We define

$$
Z_{t+1}^{\star}=\arg \max \left\{-\frac{z^{\prime}}{R_{t+1}}+\bar{h}+\beta \alpha\left[\omega(p)+W_{t+1}\left(z^{\prime}-p\right)\right]+\beta(1-\alpha) W_{t+1}\left(z^{\prime}\right)\right\},
$$

with respect to $z^{\prime} \geq 0$. In other words, $Z_{t+1}^{\star}$ is the set of optimal money holdings, if the buyer has no labor constraints and no satiation point for consumption. As we show below, the set $Z_{t+1}^{\star}$ represent the set of "targeted" money holding for the buyer.

Lemma 4 The set $Z_{t+1}^{\star}$ is convex, bounded above, and bounded away from zero. Given any $z_{t+1}^{\star} \in Z_{t+1}^{\star}$, an optimal money holdings decision for the buyer at time $t$ is:

$$
z^{\prime}=\max \left\{R_{t+1}(z-\bar{c}), \min \left\{R_{t+1}(z+\bar{h}), z_{t+1}^{\star}\right\}\right\}
$$

Proof. The set $Z_{t+1}^{\star}$ is bounded above because both $\omega(z)$ and $W_{t+1}(z)$ are concave and bounded, implying that they satisfy Inada condition at infinity. To see that it is bounded away from zero, recall that $\Omega_{t+1}^{\prime}(z) \geq \omega^{\prime}[p(z)]$ and $\lim _{z \rightarrow 0} p(z)=0$. Since $\omega(p)$ satisfies an Inada condition at zero, it follows that $\lim _{z \rightarrow 0} \Omega_{t+1}\left(z^{+}\right)=\infty$. This implies that, near zero, the right-derivative of the optimization program 
defining $Z_{t+1}^{\star}$ are strictly positive. Hence $0<\min Z_{t+1}^{\star}$. The rest of the proposition follows because the optimization program defining $Z_{t+1}^{\star}$ is concave.

The optimal rule for next period money holdings is to approach the target as closely as possible, keeping labor below the endowment, $\bar{h}$, and consumption below the satiation point, $\bar{c}$. Hence, for low values of $z$, the buyer approaches the target by working full time, and arrives next period with real balance $z^{\prime}=R_{t+1}(z+\bar{h})$. For large enough values of $z$, the buyer approaches the target by consuming up to its satiation point $\bar{c}$, and arrive next period with real balance $z^{\prime}=R_{t+1}(z-\bar{c})$. For values of $z$ in some middle range, near the target, the buyer can reach the target in one period, either by working less than $\bar{h}$ or consuming less than $\bar{c}$.

Lemma 5 The derivative of the value function is bounded, $W^{\prime}\left(0^{+}\right)<\infty$.

Proof. Choose any $z_{t+1}^{\star} \in Z_{t+1}^{\star}$ and consider the following two cases.

If $z_{t+1}^{\star} \leq R_{t+1} \bar{h}$ then, for all $z>0$ and close enough to zero, an optimal choice of money holdings is $z^{\prime}=z_{t+1}^{\star}$. Substituting this into the Bellman equation, we obtain:

$$
W_{t}(z)=z-\frac{z_{t+1}^{\star}}{R_{t+1}}+\beta \alpha \Omega_{t+1}\left(z_{t+1}^{\star}\right)+\beta(1-\alpha) W_{t+1}\left(z_{t+1}^{\star}\right),
$$

which immediately implies that $W_{t}^{\prime}\left(0^{+}\right)=1$.

If $z_{t+1}^{\star}>R_{t+1} \bar{h}$ then for all $z>0$ and close enough to zero, an optimal choice of money holdings is $z^{\prime}=R_{t+1}(z+\bar{h})$. Substituting this in the Bellman equation we obtain:

$$
W_{t}(z)=-\bar{h}+\beta \alpha \Omega_{t+1}\left[R_{t+1}(z+\bar{h})\right]+\beta(1-\alpha) W_{t+1}\left[R_{t+1}(z+\bar{h})\right] .
$$

Since $R_{t+1}>0, z^{\prime}=R_{t+1} \bar{h}$ lies in the interior of the domain of $\Omega_{t+1}\left(z^{\prime}\right)$ and $W_{t+1}\left(z^{\prime}\right)$. Given that these functions are concave, they have right-derivative at this interior point. Hence, $W_{t}(z)$ has a right-derivative at zero, i.e., $W_{t}^{\prime}\left(0^{+}\right)<\infty$.

With this result we establish:

Lemma 6 For all $z>0$, the optimal payment in the DM is strictly positive: $p_{t}(z)>0$. Moreover, the indirect utility of bringing $z$ units of real balances in the $D M, \Omega_{t}(z)$, is continuously differentiable over $(0, \infty)$ with $\Omega_{t}^{\prime}(z)=\omega^{\prime}\left[p_{t}(z)\right]$

Proof. The first point follows from the fact, shown in Lemma 5, that $W_{t+1}\left(0^{+}\right)<\infty$ but $\omega^{\prime}(0)=\infty$. For the second point consider some $z>0$. Since $p_{t}(z)>0, p_{t}(z)-\left(z-z^{\prime}\right)$ is feasible for $z^{\prime}<z$ and close enough to $z$. Therefore, for such $z^{\prime}$, we have

$$
\Omega_{t}\left(z^{\prime}\right) \geq \omega\left[p_{t}(z)-\left(z-z^{\prime}\right)\right]+W_{t}\left[z-p_{t}(z)\right]
$$

with an equality for $z=z^{\prime}$. Subtracting the inequality for $z^{\prime}<z$ to the equality for $z^{\prime}=z$, and dividing through by $z-z^{\prime}$, we obtain:

$$
\frac{\Omega_{t}(z)-\Omega_{t}\left(z^{\prime}\right)}{z-z^{\prime}} \leq \frac{\omega\left[p_{t}(z)\right]-\omega\left[p_{t}(z)-\left(z-z^{\prime}\right)\right]}{z-z^{\prime}} .
$$


Letting $z^{\prime} \rightarrow z$, we obtain $\Omega_{t}^{\prime}\left(z^{-}\right) \leq \omega^{\prime}\left[p_{t}(z)\right]$. Since we have already shown in Lemma 3 that $\Omega_{t}\left(z^{+}\right) \geq$ $\omega^{\prime}\left[p_{t}(z)\right]$, and since $\Omega_{t}(z)$ is concave, we obtain that, for all $z>0, \Omega_{t}(z)$ is differentiable with $\Omega_{t}^{\prime}(z)=$ $\omega^{\prime}\left[p_{t}(z)\right]$.

\section{A.1.3: Differentiability of the value function}

In this section we establish the differentiability of the value function and provide an explicit formula for the derivative. The main difficulty we confront is that the Envelope Theorem of Benveniste and Scheinkman does not apply to our environment, because it requires optimal choices to lie in the interior of the constraint set - in contrast, in our setting, the labor endowment constraint may bind. To address this difficulty, RincónZapatero and Santos (2009) have established an Envelope Theorem for a broad class of stationary dynamic optimization problems in which optimal choices may not lie in the interior of the constraint set, but must lie in the interior of the state space. In this section, we apply their results to our environment and we establish differentiability. The application is not immediate however, because two of their maintained assumptions are violated in our environment. First, our environment is non-stationary, since $R_{t+1}$ is not constant over time. Second, some optimal choices may not lie in the interior of the state space: namely, when a buyer chooses to deplete its money holding in full in the DM, he enters the following CM with zero money balance.

Maintained assumptions about returns. We will need two make assumptions on the path of grossreturns:

- (A1) There exists some $\underline{R}>0$ such that, for all $t \geq 0, R_{t+1}>\underline{R}$.

- (A2) $\sum_{i=1}^{\infty} \beta^{i}(1-\alpha)^{i-1} \alpha\left[\Pi_{j=1}^{i} R_{i}\right]<\infty$.

The first assumption rules out hyper-inflationary dynamics and the second assumption helps with the proof that the expected present value of marginal utilities from real balance is finite - as required to apply the argument of Rincón-Zapatero and Santos (2009). Note that both assumptions are verified for the transitional dynamics we analyze in the paper, whereby $R_{t} \rightarrow 1$ as $t \rightarrow \infty$.

Bounds on decision variables Next, we establish bounds on decision variables.

Lemma 7 The DM payment satisfies $p_{t}(z) \geq \hat{p}(z)$ for some time-invariant function, $\hat{p}(z)$, which is continuous, strictly increasing, and satisfies $\hat{p}(0)=0$ as well as $0<\hat{p}(z) \leq z$ for all $z>0$.

Proof. Suppose that $p_{t}(z)<z$. Since there is partial depletion, the first-order condition for the DM problem is

$$
\omega^{\prime}\left[p_{t}(z)\right]=W^{\prime}\left[z-p_{t}(z)^{+}\right] \leq \frac{\|W\|}{z-p_{t}(z)} \Rightarrow\left[z-p_{t}(z)\right] \omega^{\prime}\left[p_{t}(z)\right] \leq\|W\| .
$$

Consider now the equation $(z-p) \omega^{\prime}(p)=\|W\|$ for $z>0$. The left hand side is continuous and strictly decreasing in $p$, goes to infinity as $p \rightarrow 0$ and to zero as $p \rightarrow z$. Hence, the equation has a unique solution $\hat{p}(z)$, which satisfies $0<\hat{p}(z)<z$. Since the equation has a unique solution and is continuous in $(z, p)$, the 
function $\hat{p}(z)$ is continuous as well. Since $0<\hat{p}(z)<z$, we can extend the function by continuity at $z=0$ by setting $\hat{p}(0)=0$.

Clearly, when $p_{t}(z)<z$, the inequality (98) implies that $p_{t}(z) \geq \hat{p}(z)$ for all $t$. When $p_{t}(z)=z$, this inequality is also satisfied since $\hat{p}(z)<z$.

The second preliminary result is:

Lemma 8 For all $t \geq 0$, optimal money holdings are bounded below by $\underline{z}=\min \left\{\underline{R} \bar{h},\left(\omega^{\prime}\right)^{-1}\left(\frac{1}{\beta \alpha \underline{R}}\right)\right\}$.

Proof. A first-order condition for an optimal choice of target is:

$$
-\frac{1}{R_{t+1}}+\beta \alpha \omega^{\prime}\left[p_{t+1}(z)\right]+\beta(1-\alpha) W_{t+1}\left(z^{+}\right) \leq 0 .
$$

Since the value function is increasing, this implies that $\beta \alpha \omega^{\prime}\left[p_{t+1}(z)\right] \leq 1 / R_{t+1}$. Since $z \geq p_{t+1}(z)$, we obtain that $\beta \alpha \omega^{\prime}(z) \leq 1 / R_{t+1}$. Since $\omega^{\prime}(z)$ is decreasing, this implies:

$$
z \geq\left(\omega^{\prime}\right)^{-1}\left(\frac{1}{\beta \alpha R_{t+1}}\right) \geq\left(\omega^{\prime}\right)^{-1}\left(\frac{1}{\beta \alpha \underline{R}}\right) \text { for all } z \in Z_{t+1}^{\star} .
$$

The result then follows from the policy function for optimal money holdings, in equation (97).

The main proposition. We now can state our differentiability result:

Proposition 9 The value function is continuously differentiable, with:

$$
W_{t}^{\prime}(z)=\sum_{i=1}^{\infty} \beta^{i}(1-\alpha)^{i-1} \alpha\left(\Pi_{j=1}^{i} R_{t+j}\right) \omega^{\prime}\left[p_{t+i}\left(z_{t+i}\right)\right],
$$

where $z_{t+i}$ is a sequence of optimal money holdings starting starting from $z_{t}=z$.

Proof. We first use the Envelope Theorem stated in Corollary 5 of Milgrom and Segal (2002), which applies to optimization problems with parameterized constraints. To see that all the conditions are satisfied, we first note that, given $R_{t+1}>0$, there exists a single $z^{\prime} \geq 0$ and a neighborhood of $z$ such that, for all real balances in this neighborhood, $z^{\prime}$ lies in the interior of the constraint set. Note as well that the the objective function and the function defining the constraint are continuous and concave, and have partial derivatives with respect to $z$ which are continuous in $\left(z, z^{\prime}\right)$. Let the Lagrangian associated with the optimization problem (96) is:

$$
\begin{aligned}
L\left(z, z^{\prime}, \lambda\right)= & z-\frac{z^{\prime}}{R_{t+1}}+\beta \alpha \Omega_{t+1}\left(z^{\prime}\right)+\beta(1-\alpha) W_{t+1}\left(z^{\prime}\right) \\
& +\bar{\lambda}\left[R_{t+1}(z+\bar{h})-z^{\prime}\right]+\underline{\lambda}\left[z^{\prime}-R_{t+1}(z-\bar{c})\right] .
\end{aligned}
$$

where $\lambda$ denote the vector $(\bar{\lambda}, \underline{\lambda})$. Let $\Lambda^{\star}$ denote the set of Kuhn-Tucker multipliers and $\Xi^{\star}$ denote the set of optima associated with this optimization problem. These sets are non empty and compact under the stated conditions. Then by the above mentioned Envelope Theorem, we have:

$$
\begin{aligned}
& \text { for all } z \geq 0: W_{t}^{\prime}\left(z^{+}\right)=\min _{\lambda \in \Lambda^{\star}} \max _{z^{\prime} \in \Xi^{\star}} \frac{\partial L}{\partial z}\left(z, z^{\prime}, \lambda\right)=\min _{\lambda \in \Lambda^{\star}} 1+R_{t+1}(\bar{\lambda}-\underline{\lambda}) \\
& \text { for all } z>0: W_{t}^{\prime}\left(z^{-}\right)=\max _{\lambda \in \Lambda^{\star}} \min _{z^{\prime} \in \Xi^{\star}} \frac{\partial L}{\partial z}\left(z, z^{\prime}, \lambda\right)=\max _{\lambda \in \Lambda^{\star}} 1+R_{t+1}(\bar{\lambda}-\underline{\lambda}) \text {. }
\end{aligned}
$$


By taking derivative of the Lagrangian with respect to $z^{\prime}$, we can obtain natural bounds for the Kuhn-Tucker multipliers entering the above expression for the left- and right-derivatives. Namely, fix some optimal money holdings $z_{t+1} \in \Xi^{\star}$. Then, by Theorem 28.3 in Rockafellar (1970), we know that any Kuhn-Tucker multipliers $\lambda \in \Lambda^{\star}$ must satisfy:

$$
\frac{\partial L}{\partial z^{\prime}}\left(z, z_{t+1}^{+}, \lambda\right) \leq 0 \leq \frac{\partial L}{\partial z^{\prime}}\left(z, z_{t+1}^{-}, \lambda\right) .
$$

Taking derivatives explicitly and rearranging the resulting first-order condition, we obtain that for any $\lambda \in \Lambda^{\star}:$

$$
\begin{aligned}
\bar{\lambda}-\underline{\lambda} & \geq-\frac{1}{R_{t+1}}+\beta \alpha \omega^{\prime}\left[p_{t+1}\left(z_{t+1}\right)\right]+\beta(1-\alpha) W_{t+1}^{\prime}\left(z_{t+1}^{+}\right) \\
\bar{\lambda}-\underline{\lambda} & \leq-\frac{1}{R_{t+1}}+\beta \alpha \omega^{\prime}\left[p_{t+1}\left(z_{t+1}\right)\right]+\beta(1-\alpha) W_{t+1}^{\prime}\left(z_{t+1}^{-}\right) .
\end{aligned}
$$

Plugging this back into the expression for $W_{t}^{\prime}\left(z^{+}\right)$and $W_{t}^{\prime}\left(z^{-}\right)$, we obtain the inequalities:

$$
\begin{aligned}
& \text { for all } z \geq 0: W_{t}^{\prime}\left(z^{+}\right) \geq \beta \alpha R_{t+1} \omega^{\prime}\left[p_{t+1}\left(z_{t+1}\right)\right]+\beta(1-\alpha) R_{t+1} W_{t+1}^{\prime}\left(z_{t+1}^{+}\right) \\
& \text {for all } z>0: W_{t}^{\prime}\left(z^{-}\right) \leq \beta \alpha R_{t+1} \omega^{\prime}\left[p_{t+1}\left(z_{t+1}\right)\right]+\beta(1-\alpha) R_{t+1} W_{t+1}^{\prime}\left(z_{t+1}^{-}\right)
\end{aligned}
$$

Iterating forward, we obtain:

$$
\begin{aligned}
& \text { for all } z \geq 0: W_{t}^{\prime}\left(z^{+}\right) \geq \sum_{i=1}^{I} \beta^{i}(1-\alpha)^{i-1} \alpha\left(\Pi_{j=1}^{i} R_{t+i}\right) \omega^{\prime}\left[p_{t+i}\left(z_{t+i}\right)\right]+\beta^{I}(1-\alpha)^{I}\left(\Pi_{i=1}^{I} R_{t+i}\right) W_{t+1}^{\prime}\left(z_{t+I}^{+}\right) \\
& \text {for all } z>0: W_{t}^{\prime}\left(z^{-}\right) \leq \sum_{i=1}^{I} \beta^{i}(1-\alpha)^{i-1} \alpha\left(\Pi_{j=1}^{i} R_{t+i}\right) \omega^{\prime}\left[p_{t+i}\left(z_{t+i}\right)\right]+\beta^{I}(1-\alpha)^{I}\left(\Pi_{i=1}^{I} R_{t+i}\right) W_{t+1}^{\prime}\left(z_{t+I}^{-}\right),
\end{aligned}
$$

where $z_{t+i}$ denote some sequence of optimal money holdings decisions generated by (97) starting starting from $z_{t}=z$. From Lemma 8 , we know that optimal money holdings are bounded below by $\underline{\xi}$. By Lemma 7 , this implies that optimal payments in the DM are bounded below by $\hat{p}(\underline{\xi})$. This implies the upper bounds $\omega^{\prime}\left[p\left(z_{t+i}\right)\right] \leq\|\omega\| / \hat{p}(\underline{\xi})$ and $W_{t+I}^{\prime}\left(z_{t+I}^{ \pm}\right) \leq\|W\| / \underline{\xi}$. Together with assumption (A2) stated at the beginning of the section, these upper bound allow us to take limits as $I \rightarrow \infty$ in the above expressions, and we obtain:

$$
\begin{aligned}
& \text { for all } z \geq 0: W_{t}^{\prime}\left(z^{+}\right) \geq \sum_{i=1}^{\infty} \beta^{i}(1-\alpha)^{i-1} \alpha\left(\Pi_{j=1}^{i} R_{t+i}\right) \omega^{\prime}\left[p_{t+i}\left(z_{t+i}\right)\right] \\
& \text { for all } z>0: W_{t}^{\prime}\left(z^{-}\right) \leq \sum_{i=1}^{\infty} \beta^{i}(1-\alpha)^{i-1} \alpha\left(\Pi_{j=1}^{i} R_{t+i}\right) \omega^{\prime}\left[p_{t+i}\left(z_{t+i}\right)\right]
\end{aligned}
$$

Given that $W_{t}^{\prime}\left(z^{+}\right) \leq W_{t}^{\prime}\left(z^{-}\right)$, this implies that $W_{t}(z)$ is differentiable at $z$, and that the derivative is as stated in the Proposition. The derivative is continuous by Theorem 24.1 in Rockafeller (1970). 


\section{Appendix A2: Conditions for equilibria in Section 5}

Equilibria with $N=2$ From (25) and (30) steady-state equilibria with $N=2$ exist if

$$
\omega^{\prime}(2 \bar{h}) \leq 1+\frac{r}{\alpha}<\omega^{\prime}(\bar{h}) \leq\left(1+\frac{1+r}{\alpha}\right)\left(1+\frac{r}{\alpha}\right) .
$$

First, we check that $z_{1}^{1}<z_{1}^{\star}$. From (41)

$$
R_{1} \bar{h}+\left(1-\frac{1}{\gamma}\right)\left[\alpha \bar{h}+(1-\alpha) z^{\star}\right]<z_{1}^{\star}
$$

As $\gamma$ approaches 1 the left side tends to $\bar{h}$ while the right side tends to $z^{\star}$. Hence, by continuity (102) holds for low values of $\gamma$. Substituting $z_{1}^{\star}$ by its expression given by (56) this condition can be rewritten as:

$$
\gamma R_{1}<\frac{\alpha \bar{h}+(1-\alpha) z^{\star}}{\bar{h}}
$$

According to (103) the ex-post rate of return of money at time $t=0, R_{0}=1 /\left(R_{1} \gamma\right)$, must be above a threshold less than one. Second, we check that buyers holding $m_{\ell}$ units of money at the beginning of the CM of $t=0$ (before transfers) can accumulate $z_{1}^{\star}$, i.e., $h_{0}^{+}\left(m_{\ell}\right) \leq \bar{h}$. From (57) this condition can be rewritten as:

$$
(1-\alpha)\left(z^{\star}-\bar{h}\right) \leq\left(\gamma R_{1}-\alpha\right) \bar{h}
$$

The right side tends to $(1-\alpha) \bar{h}$ as $\gamma$ goes to 1 . Hence, under the condition $z^{\star} \leq 2 \bar{h}$, (104) holds for values of $\gamma$ close to 1 . Finally, we check that the $1-\alpha$ measure of agents with money balances at the beginning of the $\mathrm{CM}$ of $t=1$ can accumulate $z^{\star}$ since $z_{1}^{1}>\bar{h}$. Indeed, from the clearing condition of the money market, $\alpha z_{1}^{1}+(1-\alpha) z_{1}^{\star}=\alpha \bar{h}+(1-\alpha) z^{\star}$, i.e.,

$$
z_{1}^{1}-\bar{h}=\left(\frac{1-\alpha}{\alpha}\right)\left(z^{\star}-z_{1}^{\star}\right)>0
$$

Equilibria with $N \geq 3$ In order to guarantee that we have an equilibrium we check that $h \leq \bar{h}$ binds for the buyer of type $N-1$ but not for the type $N$. These conditions can be written as

$$
\begin{gathered}
\phi_{t} m^{N-1-t}<z_{t}^{\star}-\bar{h} \sum_{n=1}^{t} \frac{\phi_{t}}{\phi_{t-n}}-(\gamma-1) \phi_{t} M \leq \phi_{t} m^{N-t}, \quad \forall t \leq N-1 \\
\bar{h} \sum_{n=1}^{N-1} \frac{\phi_{t}}{\phi_{t-n}}<z_{t}^{\star} \leq \bar{h} \sum_{n=1}^{N} \frac{\phi_{t}}{\phi_{t-n}}, \quad \forall t \geq N,
\end{gathered}
$$

where

$$
m^{j}=j \frac{\alpha \bar{h} M}{\bar{h}\left\{1-(1-\alpha)^{N-1}[(N-1) \alpha+1]\right\}+\alpha(1-\alpha)^{N-1} z^{\star}} .
$$

We must also check that buyers have incentives to deplete their money holdings in full at all point in time, i.e.,

$$
1+\frac{1-\beta R_{t}}{\alpha \beta R_{t}} \geq \lambda_{t}(0) \text { for all } t
$$


where, from (18),

$$
\begin{aligned}
\lambda_{t}(0)= & \sum_{n=1}^{N-1} \alpha(1-\alpha)^{n-1} \beta^{n} \frac{\phi_{t+n}}{\phi_{t}} \omega^{\prime}\left[\bar{h} \sum_{u=1}^{n} \frac{\phi_{t+n}}{\phi_{t+n-u}}\right] \\
& +(1-\alpha)^{N-1} \beta^{N-1} \frac{\phi_{t+N-1}}{\phi_{t}} .
\end{aligned}
$$




\section{Appendix A3: Directed vs undirected transfers}

Proposition 10 (Undirected transfers.) A one-time money injection, $(\gamma-1) M$, through lump-sum transfers to both buyers and sellers reduces the rate of return of money, $R_{1}<1$, and it generates short-run deflation, $\phi_{0}>\gamma \phi_{1}$, if and only if:

$$
\frac{-z^{\star} \omega^{\prime \prime}\left(z^{\star}\right)}{\omega^{\prime}\left(z^{\star}\right)}>\frac{(1+\sigma) z^{\star}}{\left[z^{\star}-\left(1+\frac{\sigma}{1-\alpha}\right) \bar{h}\right] \beta \alpha(r+\alpha)} .
$$

Proof. The real balances at the beginning of $t=1$ of the buyers holding $m=0$ at the time of the money injection are

$$
z_{1}^{1}=R_{1} \bar{h}+(\gamma-1) \phi_{1} \frac{M}{1+\sigma} .
$$

The only difference with respect to (41) is the second term on the right side where $M$ is replaced with $M /(1+\sigma)$. Buyers holding $m_{\ell}$ and $m_{h}$ accumulate $z_{1}^{\star}$ solution to (43). Aggregate real balances at the beginning of $t=1$ are $\phi_{1} \gamma M=\alpha z_{1}^{1}+(1-\alpha) z_{1}^{\star}$. Assuming that the economy returns to its steady state in the $\mathrm{CM}$ of $t=1$ we have:

$$
\phi_{1} \gamma M=\frac{\alpha R_{1} \bar{h}+(1-\alpha) z_{1}^{\star}}{1-\alpha\left(1-\gamma^{-1}\right) /(1+\sigma)}=\alpha \bar{h}+(1-\alpha) z^{\star} .
$$

The last term on the right corresponds to aggregate real balances at the steady state. The rest of the proof is analogous to the reasoning in the text.

Proposition 11 (Directed transfers.) A one-time money injection, $(\gamma-1) M$, through transfers to sellers or buyers holding $m_{\ell}$ or $m_{h}$ is neutral, i.e., $R_{1}=1$. In contrast, if money is only received by the buyers with depleted money holdings, then $R_{1}<1$ and short-run deflation, $\phi_{0}>\gamma \phi_{1}$, occurs if and only if:

$$
\frac{-\omega^{\prime \prime}\left(z^{\star}\right) z^{\star}}{\omega^{\prime}\left(z^{\star}\right)}>\frac{1}{\beta(r+\alpha)}
$$

Proof. Suppose that the transfer is only received by sellers or buyers holding $m_{\ell}$ or $m_{h}$. Those agents are not constrained by their endowments when choosing real balances in the CM. In this case the rate of return of money in the short run is determined by:

$$
\alpha R_{1} \bar{h}+(1-\alpha) z_{1}^{\star}=\alpha \bar{h}+(1-\alpha) z^{\star}
$$

Relative to (49) the denominator of the left side is equal to one because the poorest buyers with depleted money balances do not receive any money. It is easy to check that $R_{1}=1$. Let us consider next a money injections through transfers to buyers with depleted money balances. Such transfers require that the monetary authority can observe the money holdings of buyers. Each one of the $\alpha$ buyers with depleted money balances at the beginning of the $\mathrm{CM}$ receives $(\gamma-1) M / \alpha$. The rate of return of money in the short-run solves:

$$
\alpha \gamma R_{1} \bar{h}+(1-\alpha) \gamma z_{1}^{*}=\alpha \bar{h}+(1-\alpha) z^{\star} .
$$

It is easy to check that $R_{1}<1$. Differentiating this equation leads to (113). 


\section{Appendix A4: Map of equilibria}

In the following we illustrate the set of equilibria for our economy for different values for $\bar{h}, r$, and $\alpha$. We adopt the following functional forms: $u(y)=2 \sqrt{y}$ and $v(y)=y$. In Figure 11 we set $r=0.04$. The colored area corresponds to equilibria with full depletion of real balances. The white area is when the equilibrium features partial depletion. Equilibria with full depletion exist when $\bar{h}$ is above a threshold. Moreover, as $\bar{h}$ increases $N$ decreases since buyers can reach their targeted real balances in a smaller number of periods.

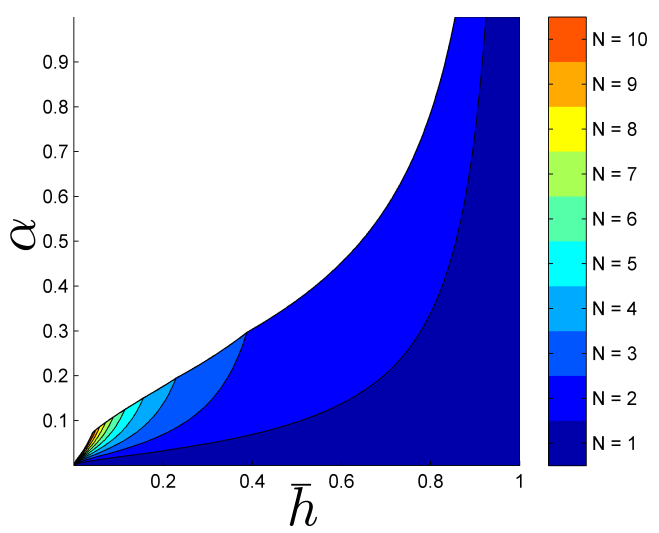

Figure 11: Typology of equilibria with full depletion in the $(\bar{h}, \alpha)$ space

In Figure 12 we allow $r$ to vary and we set $\alpha=0.1$. This figure is analogous to 5 . For a given labor endowment $N$ decreases as $r$ decreases since more patient buyers have higher targeted real balances. When $r$ is sufficiently low the equilibrium features partial depletion of real balances.

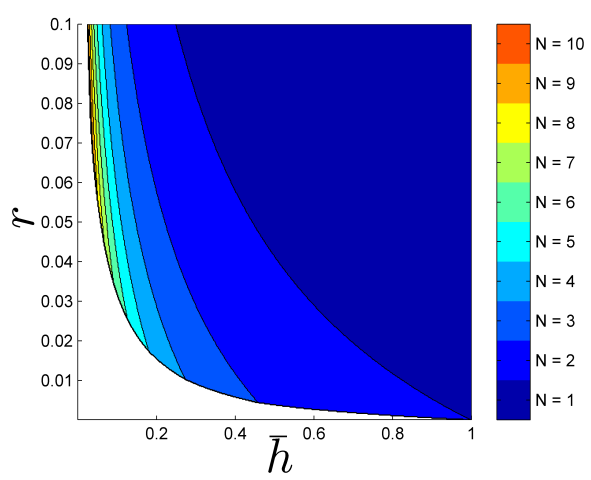

Figure 12: Typology of equilibria with full depletion in the $(\bar{h}, r)$ space 


\section{Appendix A5: Algorithm to compute value functions and stationary distribu- tions}

The algorithm to compute the value function, $W(z)$, and the distribution of real balances, $F$, at a steady-state equilibrium is composed of four steps:

Step 0. Fix some initial guess of $W_{0}(z)$ for the domain $z \in[0, \bar{z}]$, where $\bar{z}$ should be reasonably large. For example set $W_{0}(z)$ to be the closed-form case with $N=2$, and $\bar{z}=3\left(u^{\prime}\right)^{-1}(1+r / \alpha)$.

Step 1. Iterate the following $k$-th value function

$$
W_{k+1}(z)=z+\max _{\substack{h \leq \bar{h}, y \leq h+z}}\left\{-h+\beta\left[\alpha\left[u(y)+W_{k}(z+h-y)\right]+(1-\alpha) W_{k}(z+h)\right]\right\}
$$

until it reaches some tolerance level, for example $\left\|W_{k+1}(z)-W_{k}(z)\right\| \leq 10^{-6}$. Obtain the value function $W(z)=W_{k}(z)$.

Step 2. Obtain the policy function $h(z)$ and $y(z)$. Initiate $s=1,2 \ldots 10^{6}$ sample points with $z_{1}^{s}=0$.

Step 3. For each $s$, generate a uniform random variable $U_{s}$. Set $z_{t+1}^{s}=z_{t}^{s}+h\left(z_{t}^{s}\right)-\mathbb{I}_{U_{s} \leq \alpha} p\left(z_{t}^{s}\right)$.

Step 4. Iterate $z_{t}^{s}$ until $t=T=10^{5}$. Obtain the stationary distribution $F(z)$ as the empirical CDF of $z_{T}^{s}$ 


\section{Appendix A6. Numerical Algorithm to Compute the Transitional Dynamics}

Step 0. Fix a parameter that features a full-depletion stationary equilibrium with $N$ mass points, for example we set $N=4$ in the numerical example. Set a large $T>N$ number of periods of the transitional dynamics $\mathbf{R}=\left\{R_{1}, R_{2}, \ldots R_{T}\right\}$ and $\phi=\left\{\phi_{0}, \phi_{1}, \ldots \phi_{T}\right\}$, for example we set $T=100$ in the numerical example.

Step 1. Define the constraints: for all $t \geq N$

$$
\phi_{t} \gamma M=\sum_{j=1}^{N-1} \mu_{j}\left[\sum_{n=1}^{j} \bar{h} \prod_{s=1}^{n} R_{t+1-s}\right]+\mu_{N} z_{t}^{\star}
$$

and for all $t \leq N-1$

$$
\phi_{t} \gamma M=\frac{\sum_{j=1}^{t-1} \mu_{j}\left[\sum_{n=1}^{j} \bar{h} \prod_{s=1}^{n} R_{t+1-s}\right]+\sum_{j=t}^{N-1} \mu_{j} \sum_{n=1}^{t} \bar{h} \prod_{s=1}^{n} R_{t+1-s}+\mu_{N} z_{t}^{\star}}{1-\frac{1}{\gamma} \sum_{j=t}^{N-1} \mu_{j}\left[m_{j}+(\gamma-1)\right]}
$$

where

$$
m_{j}=\frac{\alpha(j-t) \bar{h}}{\bar{h}\left\{1-(1-\alpha)^{N-1}[(N-1) \alpha+1]\right\}+\alpha(1-\alpha)^{N-1} z^{\star}} .
$$

The real balances of the N-1 th agent is

$$
z_{N-1, t}=\left\{\begin{array}{l}
(N-1) h R_{0}, \text { if } t=0 \\
h\left[(N-1-t) \prod_{s=1}^{t+1} R_{t+1-s}+\sum_{j=1}^{t} \prod_{s=1}^{j} R_{t+1-s}\right], \text { if } t \in\{1 \ldots N-2\} \\
\sum_{n=1}^{N-1} h \prod_{s=1}^{n} R_{t+1-s}, \text { otherwise }
\end{array}\right.
$$

The marginal value of real balances is

$$
\lambda_{t}(0)=\sum_{j=1}^{N-1}\left\{\mu_{j} \beta^{j} \omega^{\prime}\left(\sum_{n=1}^{j} \bar{h} \prod_{s=1}^{n} R_{t+j-s+1}\right) \prod_{s=1}^{j} R_{t+j-s+1}\right\}+\beta^{N-1} \mu_{N} \prod_{j=1}^{N-1} R_{t+N-j}
$$

The sufficient condition for full depletion is

$$
1+\frac{(1+r) / R_{t}-1}{\alpha} \geq \lambda_{t}(0) .
$$

The sufficient condition for $N$ mass point is

$$
\omega^{\prime}\left(z_{N-1, t}\right)>1+\frac{(1+r) / R_{t}-1}{\alpha} \geq \omega^{\prime}\left(z_{N, t}\right)
$$

Step 2. Solve the standard constrained minimization problem: $\varepsilon \equiv \min _{\phi, \mathbf{R}}\left(R_{T}-1\right)^{2}$ subject to $R_{t}=$ $\phi_{t} / \phi_{t-1}$, (114), (115), (116), and (117). Accept the transitional dynamics $\mathbf{R}$ if the error $\varepsilon$ is less than some tolerance level, says $10^{-6}$ : after $T$ period $R_{T}$ is in the neighborhood of its steady state level 1 . Notice that the algorithm does not always guarantee to reach a solution $\mathbf{R}$ for any parameter values, as the economy may feature partial depletion or the number of mass point changes along the transition dynamics. 